\title{
Regulator Leniency and Mispricing in Beneficent Nonprofits
}

\section{Citation}

Heese, Jonas, Ranjani Krishnan, and Frank Moers. "Regulator Leniency and Mispricing in Beneficent Nonprofits." Harvard Business School Working Paper, No. 15-056, January 2015.

\section{Permanent link}

http://nrs.harvard.edu/urn-3:HUL.InstRepos:13596847

\section{Terms of Use}

This article was downloaded from Harvard University's DASH repository, and is made available under the terms and conditions applicable to Open Access Policy Articles, as set forth at http:// nrs.harvard.edu/urn-3:HUL.InstRepos:dash.current.terms-of-use\#OAP

\section{Share Your Story}

The Harvard community has made this article openly available.

Please share how this access benefits you. Submit a story.

\section{Accessibility}



H A R V A R D
B U S I N E S S
S C H O O L

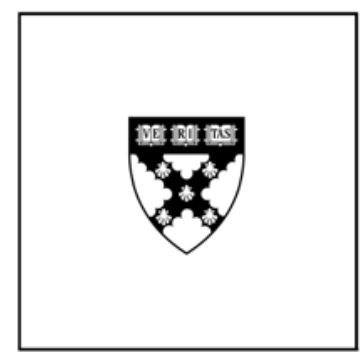

\section{Regulator Leniency and Mispricing in Beneficent Nonprofits}

Jonas Heese

Ranjani Krishnan

Frank Moers

\section{Working Paper}

15-056

January 6, 2015 


\title{
Regulator Leniency and Mispricing in Beneficent Nonprofits
}

\author{
Jonas Heese $^{\dagger}$ \\ Harvard Business School \\ Ranjani Krishnan \\ Michigan State University \\ Frank Moers \\ Maastricht University
}

Acknowledgements: We thank Ramji Balakrishnan, Leslie Eldenburg, Elina Heese, Thomas Keusch, Asís MartinezJerez, George Serafeim, Naomi Soderstrom, Patrick Vorst, and workshop participants at Drexel University, Maastricht University, Michigan State University, Temple University, WU Vienna, the 2012 Global Management Accounting Research Symposium, the 2012 New Directions in Management Accounting Conference, the 2013 AAA Management Accounting Section Mid-Year Meeting, and the 2013 European Accounting Association Conference.

${ }^{\dagger}$ Corresponding author; Morgan Hall 397, Boston, MA, 02163; email:jheese@hbs.edu; phone: 617-495-2827. 


\begin{abstract}
We posit that nonprofits that provide a greater supply of unprofitable services (beneficent nonprofits) face lenient regulatory enforcement for mispricing in price-regulated markets. Consequently, beneficent nonprofits exploit such regulatory leniency and exhibit higher mispricing. Drawing on organizational legitimacy theory, we argue that both regulators and beneficent nonprofits seek to protect their legitimacy with stakeholders, including those who demand access to unprofitable services. Using data from hospitals, we examine mispricing via "upcoding”, which involves misclassifying ailment severity. Archival analysis indicates less stringent regulatory enforcement of upcoding for beneficent nonprofit hospitals, defined as hospitals that provide higher charity care and medical education. After observing regulator leniency, beneficent hospitals demonstrate higher upcoding. Our results suggest that lenient enforcement assists beneficent nonprofits to obtain higher revenues in price-regulated markets.
\end{abstract}

Keywords: Regulator leniency; nonprofit organizations; beneficence; mispricing; upcoding 
"There are a lot of inefficiencies in the health care system, if you look at it from a purely economic standpoint. If we were just running an economy and not a society, a lot of things would be closed down or be a lot smaller than they are. But there are good social reasons to keep a hospital open in the community, even though it may not be efficient."

Kerry Weems, CMS administrator, 2009

"My job requires me to balance two important policy goals—saving taxpayer money and protecting Medicare's beneficiaries" through "preserving access and quality of care".

Marilyn Tavenner, CMS administrator, 2014

\section{INTRODUCTION}

Nonprofit organizations serve an important role in society by providing essential services that are unattractive for private enterprise or undersupplied by the government (Weisbrod, 1977, 1988). For example, nonprofit hospitals provide medical education and access to care for the uninsured (Clement, Smith, and Wheeler, 1994; Morrisey, Wedig, and Hassan, 1996; Weisbrod, 1988). Funding for medical education has faced steep reductions in recent years, which places pressures on teaching hospitals. ${ }^{1}$ The over 54 million uninsured individuals in the U.S. (in 2013) mostly use hospital emergency rooms for basic and advanced medical care, which strains hospital resources. Fulfilling medical teaching needs and serving the uninsured are therefore the two most urgent beneficent services provided by nonprofit hospitals (AAMC, 2013; Frank and Salkever, 1991; Gallup, 2014; Krishnan, Joshi, and Krishnan, 2004). Institutional as well as stakeholder theorists argue that the provision of beneficent services is essential for nonprofit hospitals' legitimacy with public as well as private stakeholders such as local, state, and federal agencies,

\footnotetext{
${ }^{1}$ The primary funding for graduate medical education (GME) is provided by the Department of Health and Human Services, through the Centers for Medicare and Medicaid Services. The Balanced Budget Act of 1997 placed limits on GME funding. In 2010 the National Commission on Fiscal Responsibility and Reform recommended further reductions in GME payments.
} 
donors, and community groups that enable hospitals to survive and thrive in their social environment (Freeman, 1984; Meyer and Rowan, 1977; Suchman, 1995). ${ }^{2}$ To enable the provision of such beneficent services, nonprofit hospitals obtain support in the form of tax exemptions, donations, and subsidies (e.g., Rose-Ackerman, 1996). Such support, however, is by and large neither reliable nor sufficient to compensate hospitals for the costs of providing these services (Chen, Bazzoli, and Hsieh, 2009).

Health care regulatory agencies such as the Department of Health and Human Services (HHS) and the Centers for Medicare and Medicaid Services (CMS) ${ }^{3}$ overtly state that access to health care is one of their core strategic goals. ${ }^{4}$ They also acknowledge the insufficient compensation for hospitals that provide charity care and medical education (e.g., CMS, 2005a; CMS, 2013). These agencies face pressures from stakeholders to curtail health care costs and crack down on medical fraud, but at the same time they also face pressures to ensure the supply of charity care and medical education. ${ }^{5}$ The fixed-price reimbursement used by most federal and private insurance programs limits the opportunities for regulatory agencies to allow for additional compensation for beneficent services using mechanisms such as differential pricing (Dranove, 1988).

This poses a quandary for both hospitals that provide unprofitable services (beneficent hospitals) and regulatory agencies. For beneficent hospitals the provision of unprofitable services

\footnotetext{
${ }^{2}$ Over recent decades nonprofit hospitals that fail to provide unprofitable services have been subject to public scrutiny by diverse stakeholders including governments, regulatory agencies, media, donors, and the public at large (e.g., Carreyrou and Martinez, 2008; Frank and Salkever, 1991; Kearns, 1994; Pear, 1990, 2006).

${ }^{3}$ CMS, formerly known as the Health Care Financing Administration (HCFA), is the largest operating division within the U.S. Department of Health and Human Services that is accountable for how it spends Medicare dollars and is responsible for safeguarding against improper payments (GAO, 2000).

${ }^{4}$ Specifically, HHS (2014b) lists that one of its primary goals is to "ensure access to quality, culturally competent care, including long-term services and supports, for vulnerable populations." Further it states: "HHS agencies are working to address health disparities experienced by minority and underserved populations who have historically had limited access to care and poor health outcomes."

${ }^{5}$ For example, the Center for Health Care Strategies (CHCS), a nonprofit health policy agency, states "as states redesign their health care safety net to meet new legislative requirements, they should consider the strategic and financial support that charity care programs will need to remain effective.” (CHCS, 2010).
} 
is essential to their mission and influences stakeholders' perceptions of legitimacy, but providing these services exposes them to financial hardships. For regulatory agencies, ensuring the supply of these unprofitable services without compromising on their role as enforcers of regulatory standards is important for their own continued legitimacy (Hiatt and Park, 2012). We explore whether this results in a dynamic process whereby regulators signal enforcement leniency towards beneficent nonprofit hospitals, which react with increased mispricing to cross-subsidize the provision of unprofitable services.

To investigate regulatory leniency, we focus on regulators' enforcement of laws intended to prevent fraudulent mispricing. In particular, we focus on upcoding, a mispricing technique that involves classifying a patient into a diagnosis-related group (DRG) that yields higher reimbursement from Medicare and other insurers. ${ }^{6}$ Upcoding is an acknowledged problem in the U.S. health care industry and has been estimated to cost in the range of $\$ 23.2$ billion in 1996 to \$44 billion in 2012 (GAO, 2000, 2013; HHS, 2013; OIG, 2001a). Regulatory agencies such as the CMS seek to prevent upcoding (CMS, 2013). ${ }^{7}$ However, these agencies are also aware that upcoding may be motivated by funding deficits to cover the cost of unprofitable services and may support such hospitals “if there is a good social reason to be served” (Iglehart, 2009).

We measure beneficence as the extent of provision of charity care and resident training. We investigate upcoding in three DRG families identified as being prone to upcoding in a study by the U.S. Department of Health and Human Services (1998). ${ }^{8}$ The high upcoding risk stems from

\footnotetext{
${ }^{6}$ DRGs identify patients with similar conditions and processes of care and requiring similar resources for treatment. Each DRG has a weight based on its relative costliness to the average for all DRGs. These weights are used for reimbursement by various programs including Medicare and other public and private insurance programs (Folland, Goodman, and Stano, 1997).

${ }^{7}$ If detected, upcoding can lead to lawsuits against the hospital (Blount and Gold, 1999). For instance, in 2000, HCA was sanctioned for unlawful billing practices and sentenced to pay a fine of more than $\$ 840$ million (Crennen, 2013).

${ }^{8}$ A DRG "family" is a group of DRGs that are associated with the same underlying body system. For example, Angina and Cardiac Arrhythmia belong to the same family, i.e., circulatory system disorders. Throughout the paper we use the terms "DRG family" and "DRG group" interchangeably.
} 
the judgment involved in assigning patients to a particular DRG and the high financial benefit from upcoding. For our empirical tests, we collect hospital and patient-level data from all nonprofit general acute-care hospitals in California for the time period 1996 to 2007. To examine regulator-hospital dynamics, we divide our analysis into two parts. First, we investigate regulatory enforcement actions for the period 1996-1998, when no reliable public information about regulatory enforcement for upcoding was available to hospitals (Silverman and Skinner, 2004); therefore there was no credible justification for hospitals to differ in their upcoding patterns. This period thus provides a good setting to examine the association between regulatory preferences and enforcement. Second, we examine the upcoding behavior of hospitals for the period 1999-2007, after they had the opportunity to observe regulatory preferences.

The first portion of the analyses uses a sample of 557 hospital-year observations and identifies hospitals convicted under the False Claims Act as of 1999 for upcoding during the time period 1996-1998. While beneficent hospitals did not have lower rates of upcoding instances compared to their less beneficent peers, they had fewer upcoding convictions, suggesting that regulatory agencies use judgment in their enforcement activities and are lax about enforcement for beneficent hospitals. The analysis controls for two hospital-specific financial motives to upcode, i.e., meeting a zero-profit earnings target (Leone and Van Horn, 2005), and incentive compensation tied to financial performance (Eldenburg et al., 2011). We find that nonprofit hospitals that meet the zero-earnings benchmark are more likely to be convicted for upcoding. This finding suggests that regulatory agencies employ stricter enforcement criteria if upcoding is driven by purely financial motives, whereas enforcement is attenuated if upcoding is driven by beneficent motives.

The second portion of the analyses uses a sample of 1,447 hospital-year observations for the period 1999-2007 and investigates whether there is a positive association between the degree 
of beneficence and upcoding. We find that a higher proportion of indigent patients is associated with more upcoding amongst a greater number of DRGs, as is a larger number of residents per hospital bed. These results hold after controlling for hospital size, patient characteristics, severity of illness, hospital performance, and market competition, among other variables. To obtain additional evidence that the positive association between degree of beneficence and upcoding is in response to the regulatory leniency provided to beneficent hospitals, we re-estimate our analysis for the time period 1996-1998, when hospitals could not observe regulatory preferences. We find that the significant relationship between upcoding and the degree of beneficence either disappears or gets weaker. These findings suggest that beneficent nonprofit hospitals engage in more upcoding than their less beneficent peers after they have had the opportunity to observe regulatory preferences conveyed in the enforcement process, but not before.

The strategic management literature emphasizes the need for studies that enhance our understanding of the complex social dynamics surrounding regulation. As Hiatt and Park (2012, 923) note, "studies have almost exclusively focused on policy making by legislators and have neglected policy implementation by regulatory agencies-a serious omission, in that regulatory agencies have more contact with businesses than legislators do via day-to-day interpretation and execution of laws.” Our study contributes by empirically demonstrating the complex dynamics between regulators and regulated organizations (Bonardi, Hillman, and Keim, 2005) that can arise in industries where both parties seek to protect their legitimacy among the same set of stakeholders. While the dominant assumption in archival research in many different fields is that firms in the same industry are exposed to similar levels of enforcement, i.e., regulation is exogenous and uniformly applied, our study articulates the dynamics of the relationship between regulators and organizations. Our results indicate that although regulators are supposed to be the “enforcers”, stakeholders expect such enforcement to be neither passive nor uniformly applied. In 
contrast to prior work, which generally argues and finds that regulatory judgment can hinder regulatory effectiveness and social welfare (e.g., Bonardi et al., 2005; Bonardi, 2004; Hillman and Keim, 1995; Holburn and Zelner, 2010; Jia, 2013), we show that in some instances, regulatory judgment may not reduce welfare. Our study offers a departure from some of the literature that adopts the premise that inconsistency in the application of regulation is driven by regulatory capture (Peltzman, 1976; Stigler, 1971) or rent seeking (Shleifer and Vishny, 1994), whereby the regulated firm gains at the expense of the customer. In our setting, although the beneficent hospital gains from upcoding, a portion of the financial gain is likely diverted towards social welfare. Our study also contributes to the strategic management literature that explores nonprofits' strategic reactions to shifts or declines in funding (Bielefeld, 1992, 1994; McMurtry, Netting, and Kettner, 1991; Nielsen, 1986; Provan, 1987). Upcoding is likely an alternative strategy for beneficent hospitals to cover costs of unprofitable services in the presence of fixedprice reimbursement. These results should be of interest to policy makers, regulatory agencies, and organizations operating in health care as well as other industries.

The following section outlines the theoretical framework of regulator-hospital dynamics and presents the hypotheses. We then describe the institutional background, and the data and methods. Following this, the results are discussed and a conclusion is offered.

\section{THEORY AND HYPOTHESES}

\section{Regulator leniency}

Regulatory agencies are set up as watchdogs of public interest (Laffont and Tirole, 1991).

As a result, the objective function of regulators is typically modelled as maximization of the weighted average of consumer surplus and producer surplus (Armstrong and Sappington, 2007; Naughton, 1989). At the same time, there is acknowledgement in research and practice that regulators do not always act to protect public interest, but could pursue personal agendas such as 
resource maximization or career advancement (e.g., Weingast, 1984; Weingast and Moran, 1983). Regulators could, for example, be lax in enforcement of large corporations as a result of political pressures or side payments (e.g., Demski and Sappington, 1987; Klein and Sweeney, 1999; Naughton, 1989; Peltzman, 1976; Stigler, 1971). Overall, economic theory does not assume that regulators are passive machines that merely implement regulatory rules; it also recognizes that regulators exercise judgment and may act in their own interest, the consumers' interest, or in the interest of the industries that they are supposed to regulate.

Sociologists articulate the legitimacy concerns of regulators (e.g., Hiatt and Park, 2012). Regulators derive legitimacy if their activities are construed by stakeholders as desirable, proper, or appropriate within a socially constructed system of norms, values, beliefs, and definitions (Suchman, 1995). Stakeholders with the strongest impact on regulators' resources, autonomy, and future success include local, state, and federal governments, who have power over regulators' budgets, nominate directors, and oversee regulatory activities. Other stakeholders include voters, professional associations, nonprofit organizations, and public interest groups, who can influence governments via lobbying activities (Hiatt and Park, 2012; Suchman, 1995). Actions of regulatory agencies that are perceived as desirable can confer legitimacy on those agencies, shaping the perceptions of stakeholders and preserving and promoting regulators' access to resources and power (Deephouse and Suchman, 2008; Delmas and Toffel, 2004; King, Felin, and Whetten, 2010). However, the assessment of the appropriateness of regulators' actions is far from straightforward, because most regulations are not "bright-line” rules, but instead contain broad language to allow for some flexibility. This leads to the necessity of using judgment in the interpretation of a regulatory violation and allows regulatory agencies to balance the goal of effective regulatory enforcement against protecting legitimacy with important stakeholders. 
Health care is an industry where such balance between regulatory enforcement effectiveness and protection of legitimacy with stakeholders is particularly complex. The U.S. health care sector is subject to extensive attention from public as well as private stakeholders (Brown, 1992). Regulators such as HHS and CMS, which have oversight responsibilities for the health care industry as a whole, are especially subject to tough and often conflicting demands for expanded access to high-quality care at lower costs. For instance, access to care for uninsured and the provision of medical education are primary concerns of state and federal governments who oversee health care regulatory agencies and make budgets allocations (e.g., Congress, 1981; Cooper, 2007; Eckholm, 2006; Kane and Wubbenhorst, 2000; Sanders, 2013). Communities that lack access to high-quality care or have a high proportion of indigent residents exert pressure on local politicians as well as health care regulators (Schuck, 1986). Consequently, regulators such as HHS and CMS make public statements that expanded access to high-quality care is their core strategic goal (e.g., CMS, 2013; HHS, 2001, 2014a). Regulators have some funds at their discretion to compensate hospitals for increased access via supplemental resources through federal or local grants and subsidies. For instance, in 2009, the HHS had a budget of \$268 million to fund the cost of treating uninsured patients. In 2004, CMS announced a budget allocation of $\$ 1$ billion over a four-year period to help hospitals to cover the costs of treating uninsured patients. Teaching hospitals are eligible for a higher reimbursement rate to help defray the costs of medical education.

However, regulatory efforts are by and large insufficient to ensure the provision of care to uninsured patients or cover all the costs of medical education (Bernstein, 2012; Chen et al., 2009; Lewin, 1997). Teaching hospitals, for instance, are required to have state-of-the-art technology, research facilities, and specialized services, which add to the already substantial cost of maintaining a residency program (Cooper, 2007). In a similar manner, for many nonprofit 
hospitals, state and federal subsidies to cover the cost of providing care for the uninsured typically only cover part of a hospital's cost (Hadley et al., 2008). In cognizance of this, regulators attempt to provide additional support by exercising the latitude provided to them in the interpretation of regulation. For instance, before the advent of fixed-price regulation, regulators implicitly approved beneficent hospitals' cross-subsidization, whereby the prices charged to some patient groups and some ailments were systematically higher than costs (Dranove, 1988; Gruber, 1994). The widespread prevalence of cross-subsidization was tacitly approved by regulators as compensation for the distortions and inequities in health care coverage (Covaleski, Dirsmith, and Michelman, 1993; Harris, 1979; Sapolsky, 1986). After the introduction of the fixed-price regulation, cross-subsidization was no longer possible. In their attempt to cover uncompensated costs, hospitals explored other strategies such as upcoding as another form of cross-subsidization, despite the fact that it is considered fraudulent billing. The CMS and HHS use a number of control and monitoring tools to reduce the risk of upcoding and can prosecute hospitals for upcoding under the False Claims Act (CMS, 2013).

Passive implementation implies that health care regulators will investigate hospitals that are most likely to upcode and uniformly prosecute and convict hospitals if they detect upcoding. Such behavior could be easily justified because of the demand by society at large to eliminate improper payments in taxpayer-funded public insurance programs (Congress, 2010; GAO, 2000). Upcoding and other types of improper payments can be substantial, e.g., they range from $\$ 23.2$ billion in 1996 to \$44 billion in 2012 (GAO, 2000, 2013; HHS, 2013; OIG, 2001a) and impose constraints on already strained public resources. Moreover, they also raise the ire of taxpayers; therefore avoiding these improper payments is a core concern of state and federal governments. However, imposing an inflexible, "one size fits all” stance and convicting all hospitals for upcoding can incur the displeasure of another set of stakeholders, who expect a "break" for 
hospitals that take care of the community's indigent and provide resident training. Regulators therefore are likely to take into consideration the benefits provided by the hospital to the community. To the extent that such assessment reveals a track record of providing unprofitable services, regulators are less likely to convict such a hospital. Indeed, the CMS interprets its enforcement mandate against improper payments in the context of the hospitals' environment of constrained resources and acknowledges that it has to "balance two important policy goalssaving taxpayer money and protecting Medicare’s beneficiaries” through "preserving access and quality of care” (Stewart and Weaver, 2014). The CMS considers health care not just an economic issue, but also a social issue and acknowledges that it will support an inefficient hospital if there are "good social reasons to keep a hospital open” (Iglehart, 2009).

We therefore argue that the complicit behavior of regulators, manifested as lower likelihood of conviction for upcoding, is driven by attempts to improve their legitimacy with stakeholders who desire unprofitable services, leading to the following hypothesis:

Hypothesis 1: Beneficent nonprofit hospitals are less likely to be convicted under the False Claims Act than other nonprofit hospitals.

\section{Beneficent nonprofit hospitals' upcoding behavior}

For nonprofit hospitals, health care access and medical education are crucial to their objective function (Weisbrod, 1977, 1988) and are supported in part by subsidies and donations. ${ }^{9}$ Nonprofit hospitals face considerable institutional pressures from political, professional, and occupational constituencies to provide these services, regardless of the extent of financial

\footnotetext{
${ }^{9}$ Hospitals are partially reimbursed by Medicaid or state/county indigent programs for a proportion of their indigent patients. The primary source of financing for teaching hospitals is Medicare, which provides a higher reimbursement rate to teaching hospitals. The rate premium depends on the number of residents trained per inpatient bed (residentto-bed ratio) leading to a per-case premium of 5.5 percent for approximately a 10 percent increase in the resident-tobed ratio. Such premium also makes it more beneficial for teaching hospitals to engage in upcoding in general. In addition, nonprofits are exempted from property taxes and from the corporate income tax (Frank and Salkever, 1994).
} 
support. However, these institutional pressures are not uniformly imposed (DiMaggio and Powell, 1983; Krishnan et al., 2004; Ruef and Scott, 1998; Scott, 2001). For instance, nonprofit hospitals typically have boards with representatives from the local community who place demands for the provision of unprofitable services. Private donations as well as state and federal funding are often conditional on providing unprofitable services (e.g., Okten and Weisbrod, 2000). These institutional forces set the framework for establishing and monitoring the nonprofit’s stock and flow of legitimacy capital (Krishnan et al., 2004). Curtailing unprofitable services and the concomitant adverse publicity can hurt the nonprofit's legitimacy (Carreyrou and Martinez, 2008; Krishnan et al., 2004; Pear, 1990, 2006).

However, organizations are not passive recipients of whatever legitimacy rewards they are granted by stakeholders. Managers can monitor, control, and influence the legitimation process. Stakeholder management theory depicts legitimacy as an operational resource that organizations extract from their environments and employ in pursuit of their goals (Ashforth and Gibbs, 1990; Dowling and Pfeffer, 1975). If provision of unprofitable services helps manage a nonprofit organization's legitimacy with stakeholders that are critical to its success, then the nonprofit will ensure that these services are provided (Freeman, 1984; Suchman, 1995) and attempt to manage the financial losses suffered in the process.

There are many mechanisms by which organizations can conform to stakeholders' expectations; some are symbolic or ritualistic rather than tangible or real (Pfeffer, 1981; Suchman, 1995). For example, nonprofit hospitals could advertise that they provide unprofitable services but not have the resources allocated to provide these services. Indeed, several nonprofit hospitals have been criticized for the insufficient provision of unprofitable services over recent decades (e.g., Carreyrou and Martinez, 2008; Frank and Salkever, 1991; Kearns, 1994; Pear, 1990, 2006). For beneficent hospitals, where the provision of unprofitable services is tangible 
rather than symbolic, the concern is to bridge the resource gap. Though upcoding allows beneficent hospitals to recoup some of these resources, it could lead not only to loss of legitimacy and reputation but also financial costs such as penalties and the potential loss of nonprofit taxexempt status. Therefore, upcoding strategies have to be applied cautiously, after assessment of the benefits versus costs. That is, hospital managers need to determine how best to comply with regulations such that their legitimacy remains intact without seriously undermining their financial resources (Edelman, 1992; Edelman and Suchman, 1997; Edelman, Uggen, and Erlanger, 1999).

All hospitals can benefit from upcoding, as it increases revenue, and consequently, profit. Organizations test and collectively construct the form and boundaries of compliance in a way that meets regulatory demands yet preserves managerial interests (Edelman, 1992). If beneficent hospitals recognize that they are subject to less stringent regulatory enforcement as predicted in H1, they can upcode more extensively than their less beneficent peers without fear of reduced legitimacy. We argue that, to meet their resource needs, beneficent hospitals upcode more than their non-beneficent peers. This leads to the following hypothesis:

Hypothesis 2: Beneficent nonprofit hospitals upcode to a greater extent than other nonprofit hospitals.

INSTITUTIONAL BACKGROUND, DATA AND RESEARCH METHOD Institutional background: Upcoding by U.S. hospitals and its enforcement

Medicare patients account for about 50 percent of a typical U.S. hospital's revenues (Torio and Andrews, 2013). Medicare pays a fixed price per patient depending on the patient's 
diagnosis-related group (DRG) based on the treatment and corresponding cost. DRG-based reimbursements are also used by most major insurers (Reinhardt, 2006). ${ }^{10}$

The DRG is assigned as follows. When a patient is admitted, the attending physician makes a report of the patient's condition and the recommended procedures and treatment. This report is then forwarded to the hospital's medical coders, who assign the patient to a specific DRG at the time of discharge. ${ }^{11}$ Although this assignment is based on the patient's medical record, there is latitude in assigning a patient to one DRG versus the other. For example, suppose a patient is admitted with respiratory infections and does not exhibit any complicating factors. This patient should be assigned to DRG 80, for which the hospital will receive $\$ 4,377.50$ reimbursement. ${ }^{12}$ By upcoding the patient to DRG 79, i.e., respiratory infections and inflammations with complications, the hospital will obtain a reimbursement of $\$ 8,188.50$, which is a revenue gain of \$3,811 without any corresponding cost. To upcode from DRG 80 to DRG 79, the hospital has to add a complicating or comorbidity (cc) factor such as anemia, asthma, diabetes, depression, hypertension, or ulcer, among others, to the patient's medical record. ${ }^{13}$

Hospital management can use several mechanisms to facilitate upcoding (Dafny, 2005). For instance, Silverman and Skinner (2004) provide anecdotal evidence that hospital management induces pressure on coders to engage in upcoding. Alternatively, physicians can be persuaded to change their diagnoses to increase revenues, or the hospital may deliberately falsify patient records.

\footnotetext{
${ }^{10}$ Medicare is an insurance program for individuals over 65 years and is administered by the U.S. government and financed by payroll taxes. Medicaid is an insurance program for families and individuals with low income and is financed by state and federal governments.

11 "Medical coder" is a professional qualification and thus requires obtaining certification based on educational background and successful completion of a qualifying examination.

${ }^{12}$ These amounts are based on the average base rate for the year 2005, which was $\$ 5,150$ for a DRG weight of 1 (CMS, 2010; OIG, 2001b).

${ }^{13}$ Note that the diagnosis of some of these complicating factors such as asthma or depression requires judgment.
} 
Since 1990, the General Accounting Office of the United States (GAO) has designated Medicare a high-risk program that is vulnerable to improper payments (GAO, 2000). Studies by government agencies found that upcoding and other types of improper payments ranged from $\$ 23.2$ billion in 1996 to $\$ 44$ billion in 2012, comprising $10-14 \%$ of total Medicare payments (GAO, 2000, 2013; HHS, 2013; OIG, 2001a). ${ }^{14}$ Accordingly, health care regulators define the prevention of improper payments as one of their strategic goals and use a number of control and monitoring tools to reduce the risk of upcoding (CMS, 2013). Two such tools include The Hospital Payment Monitoring Program and The Comprehensive Error Rate Testing Program, which check medical records to estimate "whether the medical services paid for were allowable, medically necessary, accurately coded and sufficiently documented” (CMS, 2004). ${ }^{15}$ Hospitals that upcode can also be convicted under the False Claims Act (31 USC. §§ 3729-3733), which penalizes persons and companies who defraud governmental programs such as Medicare. Qui tam actions that are part of the False Claims Act are a powerful instrument against upcoding. ${ }^{16}$ In qui tam actions whistleblowers with direct knowledge of the fraud scheme initiate the litigation on behalf of the government. The Department of Justice (DOJ) in conjunction with other agencies such as CMS then makes a judgment on whether to investigate the allegations and intervene (DOJ, 2012).

\section{Data}

We test the hypotheses using data from nonprofit hospitals in one state (California) to control for inter-state variations in enforcement activities. Financial and patient data from all

\footnotetext{
${ }^{14}$ These amounts also include payments for services not rendered, payments for services medically unnecessary, and services billed without documentation.

${ }^{15}$ Other instruments to prevent upcoding include the requirement for hospitals to use "grouper" software that can partially prevent upcoding through built-in checks; the code of ethics, which is the professional standard for the medical coder developed by the American Health Information Management Association (AHIMA); and the education provided by AHIMA, which emphasizes the undesirability of upcoding (Steinbusch et al., 2007).

${ }^{16}$ During the period of our study about $80 \%$ of health care fraud cases were qui tam actions (TAF, 2007).
} 
nonprofit general acute-care hospitals located in California are collected from the Office of Statewide Health Planning and Development (OSHPD) for the time period 1996 (the first year when patient-level data using DRGs are available) to 2007. We focus on general acute-care hospitals and exclude specialty hospitals such as children's hospitals, substance-abuse hospitals, and psychiatric hospitals, whose reimbursement rates, production functions, and patient mixes differ (Eldenburg et al., 2011).

We examine upcoding for three distinct DRG families identified by the U.S. Department of Health and Human Services (1998) as being prone to upcoding and have been used in prior research (Becker, Kessler, and McClellan, 2005; Silverman and Skinner, 2004). ${ }^{17}$ These DRG families are listed as high upcoding risk for two reasons. First, classification of a patient to a particular DRG within each of these families involves considerable judgment; therefore it is easier for the hospital to make a case that the DRG assignment was based on a medical assessment. Second, these DRG families offer financial incentives to upcode. These three DRG families are general respiratory ailments (DRG79), circulatory system disorders (DRG144), and diabetes and metabolic disorders (DRG296). ${ }^{18}$

Table 1 provides an overview of the DRG families at high risk for upcoding and the financial incentives obtained, which are a function of the case weight of each DRG. ${ }^{19}$ Based on the weight differences within a family and the resulting financial incentives, we classify DRG79 as the high-incentive family, DRG144 as the medium-incentive family, and DRG296 as the low-

\footnotetext{
${ }^{17}$ Use of these DRG families in the analysis provides us with a conservative measure of upcoding, because we focus on DRGs that are known as being prone to upcoding. Therefore, enforcement actions are likely to be high for these DRGs, reducing the extent of upcoding.

${ }^{18}$ The name indicates the DRG with the highest weight within the family. For a detailed description of DRG79 see Silverman and Skinner (2004).

${ }^{19}$ CMS assigns a unique case weight to each DRG. The case weight reflects the average level of resources for an average Medicare patient belonging to the DRG, relative to the average level of resources for all Medicare patients. The case weights are intended to account for cost variations between different types of treatments. More expensive conditions are assigned higher DRG case weights (CMS, 2005b; OIG, 2001b).
} 
incentive family. To calculate the specific upcoding incentive in dollars, we apply the hospital's base rate for a DRG weight of 1 . This rate is adjusted for area-specific wage differences and thus differs across hospitals. The average base rate for the year 2005 for a DRG weight of 1 is $\$ 5,150$ (CMS, 2010; OIG, 2001b). We use this rate as the base for the dollar values reported in Table 1, Panel B, from which it can be seen that hospitals have substantial incentives to upcode depending on the DRG family. Table 1, Panel C provides an overview of the average discharges in each of these DRG families per hospital and year in an absolute as well as relative sense. Taken together, these three DRG families represent at least ten percent of all discharges in the average hospital per year.

- Table 1 here -

In our empirical tests, the time period 1996-2007 is divided into two sub-periods with crucial differences in regulators' enforcement of hospitals' upcoding behavior. In particular, before the release of the aforementioned HHS study in 1998, regulators were not aware of the variations in upcoding risk of different DRG families. Consequently, there was no credible justification for hospitals to differ in their upcoding patterns due to differences in regulatory oversight. Only after the release of this study did regulators have knowledge about the variability in upcoding risk and could start enforcement actions. Therefore, to test our theory about the interplay between regulatory leniency and upcoding by beneficent nonprofits, we divide our analysis into two parts.

For the first part, we investigate regulatory enforcement actions for the period 1996-1998. By investigating enforcement actions for upcoding conducted before regulators were aware of the higher upcoding risk posed by these three DRG families, we can examine whether beneficent nonprofit hospitals enjoyed less stringent regulatory enforcement than their non-beneficent peers. Thus, to test H1, we use a sample of 557 hospital-year observations for the period 1996 to 1998 
and identify hospitals that were convicted for upcoding from False Claim Act settlement agreements of the DOJ as of 1999 for upcoding during the time period 1996-1998.

Second, we focus on the time period 1999-2007, which allows us to examine whether beneficent hospitals, after they have observed regulatory preferences conveyed in the enforcement process, exploit this regulatory leniency and upcode more than their non-beneficent peers. To test H2 we use a sample of 1,447 hospital-year observations for the period 1999-2007 and investigate whether there is a positive association between the provision of unprofitable services and upcoding in the three aforementioned DRG families.

\section{Research method}

Test of $\mathrm{HI}$

H1 proposes that regulators are less likely to convict beneficent nonprofit hospitals under the False Claims Act. We examine the likelihood of being convicted for upcoding using the following logistic regression model, where subscript $i$ represents the hospital and $t$ the year:

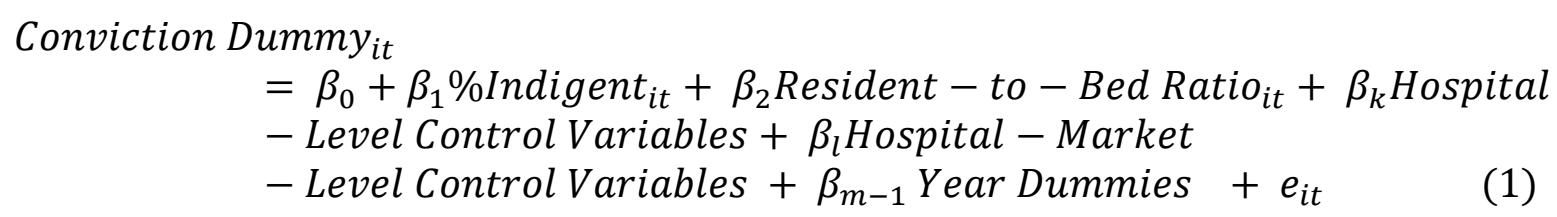

Dependent variable. The Conviction Dummy is an indicator variable that is equal to one in the years a hospital engaged in upcoding as documented in the False Claims Act convictions, and zero otherwise. To identify convicted hospitals, we collect data from the False Claims Act settlement agreements published by the U.S. Department of Justice, which allows us to identify the exact period in which the convicted hospitals engaged in upcoding.

Predictor variables. Our measures of beneficence are indigent care (\%Indigent), which is the share of indigent patients as a percentage of the hospital's total patient population (measured in patient days) and medical education, defined as the number of residents per inpatient bed 
(Resident-to-bed ratio). $\mathrm{H} 1$ predicts a negative coefficient on $\beta_{1}$ and $\beta_{2}$, i.e., a higher percentage of indigent patients and a higher resident-to-bed ratio will be associated with a lower likelihood of conviction.

Hospital-level control variables. We use several variables that control for the hospital's operations and its financial condition. These include two hospital-specific motives to engage in upcoding, i.e., to meet a zero-earnings benchmark (Eldenburg et al., 2011; Hoerger, 1991; Leone and Van Horn, 2005) and to obtain incentive compensation (Brickley and Van Horn, 2002; Eldenburg and Krishnan, 2003; Lambert and Larcker, 1995). To identify hospitals that just meet the zero-earnings benchmark, we group hospital-years into intervals based on net income divided by total assets at the beginning of the year. Following Degeorge, Patel, and Zeckhauser (1999), we determine our categories of scaled earnings based upon $2(\mathrm{IQR}) \mathrm{n}^{-1 / 3}$ leading to a bin width of $0.02 .^{20}$ Thus, hospitals whose net income divided by lagged total assets lies in the interval $[0$, 0.02] are identified as having just met the benchmark, and are coded as 1 in the Zero Earnings Benchmark Dummy.

To construct the incentive compensation variable, we conduct a hospital-level variable of pay for performance (P4P). We follow Eldenburg et al.’s (2011) version of Sloan’s (1993) model and regress the change in log of managerial compensation on the change in return on asset $(R O A)$. Since our dataset does not include compensation details for individual managers or the CEO, we use the annual sum of direct salaries, bonuses, and benefits of the top hospital administrators including the CEO, Medical Director, Nursing Director, and their assistants as our measure of compensation (Total Compensation) (Eldenburg et al., 2011). We scale this variable by the number of full-time equivalent employees (FTEs) in the top administrative team to obtain an individual score. We also include the Herfindahl-Hirshman index $(H H I)$ to control for the

${ }^{20} I Q R$ is the sample interquartile range and $n$ is the number of observations. 
influence of competition on incentive compensation and the standard deviation of ROA over three years to control for earnings volatility $(\operatorname{StdROA})$. We exploit the panel structure of our dataset and estimate the following model for the time period 1996 to 2007 using panel-specific random parameters:

$$
\Delta \log \left[\frac{\text { Total Compensation }_{i t}}{F T E_{i t}}\right]=n_{i 0}+n_{i 1} \Delta R O A_{i t}+n_{i 2} H H I_{i t}+n_{i 3} \text { StdROA }_{i t}+e_{i t}
$$

where subscript $i$ relates to an individual hospital and $t$ to year. Based on the coefficient $n_{i 1}$, which is our hospital-specific measure of P4P, we create a dummy (P4P Dummy) that equals one for all hospitals that have a positive $n_{i l}$.

Equation 1 includes the hospital's return on asset $(R O A)$. A higher level of profitability could likely increase regulators' scrutiny towards a hospital's coding practices. We also include the Altman Z-score (Altman, 1968) (Zscore) to capture the level of financial distress of a hospital. Soderstrom (1993) provides some evidence that hospitals in poor financial condition engage in more upcoding. We adjust the original formula and replace the market value of equity with the book value of equity (Altman and Saunders, 1997). To control for the hospital's patient mix, we include the percentage of Medicare patients (\%Medicare) treated by the hospital measured in patient days. ${ }^{21}$ Although the DRG classification system is used by Medicaid as well as most major insurers, Medicare is the only insurer that fully links reimbursement to the DRG classification system (Reinhardt, 2006).

We control for the hospital's case mix index $(C M I)$, which captures the average severity of illness of patients and controls for the potential that a beneficent hospital might admit more severely ill patients. We also control for hospital size by including the natural logarithm of the

\footnotetext{
${ }^{21}$ As a robustness check, we also estimate the model using the percentage of Medicare patients treated by the hospital measured in patient discharges for the three specific DRG families (DRG79, DRG144, and DRG296). All results remain the same (untabulated).
} 
number of discharges (Log Discharges), as larger hospitals might have greater regulatory clout (Carpenter, 2004). Furthermore, we include the natural logarithm of the number of board members (Log Boardsize) to control for monitoring effectiveness. A larger board might lead to a lower monitoring effectiveness because of dysfunctional behavior, such as free-rider problems (Aggarwal, Evans, and Nanda, 2011; Yermack, 1996), and thus enable more upcoding. We further address the possibility that a hospital is church-owned (Church Dummy) and include additional controls for hospital membership in a multi-hospital system (System Dummy) and location in a rural area (Rural Dummy).

Hospital-market-level control variables. We include the Herfindahl-Hirshman index (HHI) to measure the level of competition within a local hospital market (Kwoka Jr, 1985). Consistent with prior research (Silverman and Skinner, 2004; Wennberg and Cooper, 1999), we use hospital service areas to determine local hospital markets. Higher competition might lead to more financial pressure and thus encourage more upcoding (Silverman and Skinner, 2004). Finally, we obtain data on the median household income per hospital service area from the U.S. Census Bureau and include the natural logarithm of that income (Log Median Household Income) to control for population differences across local hospital markets.

Our final sample for testing H1 consists of 203 nonprofit hospitals and 557 hospital-year observations. Table 2 provides an overview of hospitals convicted after 1998 for conducting upcoding during the time period 1996-1998. The number of convictions has a slightly increasing trend over the time period of our analysis, both in an absolute as well as relative sense. Table 3 provides an overview and definitions of the variables we use. Descriptive statistics for the sample used to test $\mathrm{H} 1$ are summarized in Table 4. The mean (median) revenue for the sample is $\$ 232$ million (\$168 million). The mean (median) net income for the sample is $\$ 4.77$ million (\$1.91 million). Mean (median) total assets are $\$ 120$ million (\$78 million). The mean (median) return on 
assets is 3.1 percent (3.4 percent). The mean (median) number of discharges is $9,389(8,079)$. The skewness of these distributions suggests that the sample includes more small hospitals than large hospitals, which is consistent with prior studies (Eldenburg et al., 2011). The average hospital has about 40.9 percent Medicare patients, a case mix index of 1.08, and 15 board members. Roughly 13.9 percent of the hospitals are located in rural areas, 22.4 percent are church-owned, and almost half (49.7 percent) belong to a system. The mean (median) Herfindahl-Hirshman index is 0.20 (0.12), and the mean median household income is $\$ 39,460$. On average 11.4 percent of the hospitals just meet the zero-earnings benchmark. About 43.6 percent of the hospitals in our sample have incentive compensation based on financial performance. About 1.24 percent of all patients treated are indigent, the mean resident-to-bed ratio is 4.5 percent, and about 22.5 percent of hospitals in our sample provide medical education.

- Tables 2, 3, and 4 here -

\section{Test of $\mathrm{H} 2$}

H2 predicts that subsequent to observing regulatory enforcement behavior, beneficent nonprofit hospitals upcode more than other hospitals. To test H2 we investigate the association between upcoding and the extent of provision of two unprofitable services within and across DRG families using three different dependent variables in a system of three equations. We estimate the equation system using seemingly unrelated regressions (SUR) (Zellner, 1962), which takes into consideration the correlation in the error terms across equations (Wooldridge, 2002). This method is appropriate because upcoding strategies are likely to be associated across DRG families. That is, a hospital that upcodes in the DRG79 family either has a higher likelihood of upcoding in DRG144 and DRG296 families if it is an aggressive upcoder, or has a lower likelihood of upcoding in the latter two families if it is a cautious upcoder. Therefore, our three equations are unlikely to be independent. To test our assumption, we conduct a Lagrange 
Multiplier (LM) test proposed by Breusch and Pagan (1980). The LM test statistic suggests that the residuals of our three equations are not independent $(p<0.001)$. Therefore, we use the following SUR model where subscript $i$ represents the hospital, $t$ the year:

\section{DRG Ratio $X_{i t}$}

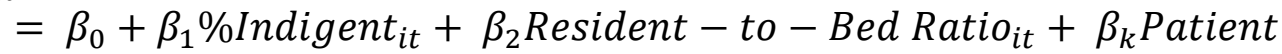

- Level Control Variables $+\beta_{l}$ Hospital - Level Control Variables

$+\beta_{m}$ Hospital - Market - Level Control Variables

$+\beta_{n-1}$ Year Dummies $+e_{i t}$

Dependent variables. $X$ is either DRG Ratio 79, DRG Ratio 144, or DRG Ratio 296. There are three equations, one for each DRG family. Our three dependent variables are calculated as the ratio of the number of patients coded into the Top DRG divided by the sum of patients discharged from all DRGs within a family.

Patient-level controls variables. To control for other factors that may drive the proportion of patients in each DRG within a family, we include the first lag of the DRG ratio (DRG Ratio $X_{t-}$ 1), the Charlson index (Charlson Index X), and the mortality rate (Mortality Rate X) within the DRG. The Charlson index captures the weighted average of a patient's health status within the specific DRG family (Charlson et al., 1987). The index assigns weights (1, 2, 3, 6) based on comorbidity (e.g., weight 1 for diabetes, weight 6 for metastatic solid tumor) and age (0 to 5; where 1 point is assigned for each decade starting at 50, e.g., 40 to $49=0$; 50 to $59=1$ ). The weighting is based on the number of patients per DRG within a family. In addition, we include a separate Charlson index calculated for the indigent patient population within the specific DRG family only (Charlson Index Indigents $X$ ) to control for the possibility that indigents are more severely ill when they demand medical services (Hsia and Shen, 2011). The underlying idea of the Charlson index is that the more severely ill its patients (i.e., the higher the index) the more likely a hospital is to have patients in the Top DRG of the respective DRG family. However, if the documentation of comorbidities is adjusted by hospitals to justify their coding choice (CMS, 
2004; Silverman and Skinner, 2004), then including the Charlson index as a control leads to an underestimation of the underlying upcoding behavior. Thus, our measure of upcoding is conservative. The mortality rate reflects the proportion of patients who died within a specific DRG while at the hospital and the health status of the patient population. Other control variables are included as explained in the test of $\mathrm{H} 1$.

Our final sample for testing $\mathrm{H} 2$ consists of 187 nonprofit hospitals and 1,447 hospital-year observations. Descriptive statistics are summarized in Table 5. An average of 22.8 percent of patients is coded into the Top DRG for family DRG79, 14.6 percent for family DRG144, and 33.7 percent for family DRG296. The Charlson index and the mortality rate for family DRG79 (4.28 and 6.1 percent) are higher on average than for the other two groups (3.44 and 3.45 Charlson index and 1.5 and 1.6 percent mortality rate, respectively). Thus, patients belonging to DRG79 have on average a lower health status. The maximum values of the Charlson indices for indigent patients (4 for DRG79, 3.25 for DRG144, and 3 for DRG296) are lower than the mean of the overall Charlson index, indicating that the few indigent patients treated in these DRG families are on average not more severely ill than other patient populations. As the descriptive statistics for the other variables are comparable to the sample for testing H1, we do not describe them here in detail.

- Table 5 here -

\section{RESULTS}

\section{Test of $\mathbf{H 1}$}

Table 6, Panel A, shows the results of estimating equation 1, which examines the likelihood of being convicted for upcoding. The negative and significant coefficient on the share of indigents $\left(\beta_{1}\right)$ and the resident-to-bed ratio $\left(\beta_{2}\right)$ indicate that hospitals with a higher proportion of indigent patients and a higher proportion of residents are less likely to be convicted for upcoding. 
The coefficient estimates are not only statistically significant but also point to economic significance as reported in Table 6, Panel B. In particular, the likelihood of conviction for a hospital in the bottom quartile of share of indigents increases by about $26 \%$ relative to a hospital in the top quartile. The likelihood of conviction for a hospital in the bottom decile of residents per bed increases by about $17 \%$ relative to a hospital in the top decile. The coefficient on the benchmark dummy is marginally significant ( $p=0.096$, two-tailed), suggesting that hospitals that have just met the zero earnings benchmark are more likely to be convicted for upcoding. These results are consistent with $\mathrm{H} 1$; regulators are less likely to convict beneficent nonprofit hospitals. In addition, regulators are more likely to convict hospitals that just meet the zero-earnings benchmark.

We also explore the overall level of upcoding during 1996-1998 compared to 1999-2007. Table 6, Panel C indicates that there was higher upcoding in the DRG79 and DRG296 families during 1996-1998 compared to 1999-2007 ( $t$-values of difference are 8.089 and 6.007 respectively, $p<0.01)$. These results suggest that upcoding in DRG79 and DRG296 was higher in 1996-1998 before hospitals could observe regulatory actions.

The control variables indicate that church hospitals, members of a hospital system, and hospitals in more concentrated markets are more likely to be convicted. A higher case mix index, i.e., a sicker patient pool and correspondingly higher information asymmetry, increases both the ability to upcode and the likelihood of conviction. In sum, the results indicate that regulators appear to be paying attention to hospitals that have market power or other opportunities for rent extraction. Thus, their lower rate of conviction of beneficent hospitals is likely to be a deliberate strategy rather than lack of oversight.

- Table 6 here - 


\section{Test of $\mathbf{H} 2$}

Table 7 presents the results of estimating the system of three equations using SUR. Recall that H2 states beneficent hospitals upcode to a greater extent than their less beneficent peers. The results indicate a positive and significant coefficient on \%Indigents $\left(\beta_{1}\right)$ for both the high- and the medium-incentive groups. The coefficient on the resident-to-bed ratio $\left(\beta_{2}\right)$ is positive and significant for all three DRG families. These results indicate support for H2-beneficent hospitals exhibit higher upcoding. The results also indicate a positive and significant coefficient on the benchmark dummy for the high-incentive DRG family (DRG79). Therefore, hospitals that have just met the zero-earnings benchmark are more likely to have upcoded in the high-incentive DRG family, but not the medium- or low-incentive DRGs. Upcoding occurs across the board for beneficent hospitals, whereas when the motive is to meet the zero-earnings benchmark, upcoding occurs only in the high-incentive DRG.

- Table 7 here -

Incentive compensation ( $P 4 P$ Dummy) is not associated with higher upcoding. Hospitals located in more competitive markets upcode to a greater extent in the high-incentive DRG group. Hospitals that are financially healthier, i.e., have a higher Z-score, upcode less in the highincentive DRG group. Higher CMI is associated with a higher upcoding ratio, suggesting that hospitals with a sicker patient pool and correspondingly higher information asymmetry upcode more. System membership is associated with higher upcoding in the high- and low-incentive DRG groups.

\section{Robustness tests}

To provide more robust evidence that the positive association between the provision of unprofitable services and upcoding is driven by beneficent hospitals’ legitimacy advantage, we re-estimate our system of three equations for the time period 1996-1998, during which hospitals 
could not observe regulatory enforcement. These results are presented in Table 8. Consistent with our theory, a comparison of the estimation results in Tables 7 and 8 indicates that the significant relationship between upcoding and the two unprofitable services either disappears (for the \%Indigents variable) or is not prevalent across all three DRG families (Resident-to-Bed Ratio). Overall, the results of our robustness test indicate that beneficent hospitals upcoded more aggressively during 1999-2007, after they had observed regulator leniency.

- Table 8 here -

Although the SUR estimation takes into consideration the possibility that the upcoding behaviors in the three DRG families are jointly determined, we also consider two-stage least squares (2SLS) as an alternate econometric specification (Wooldridge, 2002). Specifically, the coding behavior for one DRG family (DRG Ratio $X$, where X could be DRG Ratio 79, DRG Ratio 144, or DRG Ratio 296) and the two other DRG families (DRG Ratio Y and DRG Ratio Z, where $\mathrm{Y}$ and $\mathrm{Z}$ are the two other DRG families) might be jointly determined, leading to a potential simultaneous-equation bias. Hence, we also include the potentially endogenous dependent variables as control variables (DRG Ratio $Y$ and $D R G$ Ratio $Z$ ) in our model.

To use 2SLS, we require instrumental variables (IVs) that are correlated with our potentially endogenous variables, i.e., $D R G$ Ratio $Y$ and $D R G$ Ratio $Z$, but not with the error term (Wooldridge, 2002). Thus, the instruments have to be relevant and exogenous. In our setting the Charlson index and the mortality rate are likely to meet the requirements for IVs. It seems reasonable that the average health status of DRG families $\mathrm{Y}$ and $\mathrm{Z}$, measured by the mortality rate and the Charlson index, are correlated with the coding outcome in these families (relevance) and, furthermore, not related to the coding outcome of DRG family X (exogeneity). Tests of the relevance and exogeneity of the instruments confirm that our instruments are valid. A Hausman (1978) test indicates no evidence of a simultaneity bias. 
We re-estimate our model employing alternative measures for our independent variables. First, we adjust our benchmark dummy and define hospitals whose net income divided by lagged total assets lies in the intervals $[0,0.01]$ and $[0,0.03]$, respectively, as having just met the benchmark. Applying these different intervals leads to qualitatively similar results. Finally, we construct the P4P dummy by using change in net income and the standard deviation of net income over three years instead of ROA. Our results remain unchanged.

\section{DISCUSSION AND CONCLUSIONS}

Economic theory acknowledges that regulators have preferences that may vary across the firms that they regulate. However, these preferences have usually been studied either from the perspective of regulatory capture (whereby the regulator starts operating for the benefit of the organization it is supposed to regulate) or from the perspective of the political economy of the supply of regulation to serve politicians' ambitions. The empirical literatures in finance and accounting have typically used a narrower perspective and treat regulations as exogenously imposed and consistently applied to all organizations. The strategy and sociology literatures, on the other hand, have recognized the endogeneity between regulations and organizations and the fact that there is a complicated and dynamic process by which organizations influence regulation as well as draw boundaries regarding appropriate compliance—boundaries that can vary within and across industries. In this study, we empirically explore such differentiated boundaries in the context of the health care industry and the consequence of such differentiation on hospitals' strategic pricing choices.

Specifically, we posit that nonprofits that provide unprofitable services (beneficent nonprofits) are less likely to face regulatory enforcement for mispricing in price-regulated markets and, consequent to observing this regulatory leniency, exhibit more mispricing. We draw on organizational legitimacy, institutional, and stakeholder management theories to argue that the 
actions of both regulators and nonprofits are motivated by a desire to protect legitimacy not only with stakeholders such as taxpayers and voters who demand compliance stringency, but also other sets of voters, nonprofits, and special-interest groups who demand access to unprofitable health care services.

We focus on nonprofit hospitals that provide medical education and access to care for the uninsured. The provision of these socially desirable but unprofitable services is essential for hospitals' legitimacy with important stakeholders such as local, state, and federal governments, donors as well as other community groups. We examine whether beneficent nonprofits explore mispricing via "upcoding”, which involves classifying an ailment as more severe than it actually is, to financially compensate for the provision of unprofitable services. Regulatory agencies such as CMS are devoted to prevention of such mispricing (CMS, 2013). One set of stakeholders expects strict policing from regulators and demands that they crack down on fraudulent activities such as mispricing. Another set of stakeholders recognizes the substantial distortions in access to health care and is wary that unilateral imposition of regulations could widen the access chasm. The latter set of stakeholders, for example, would favorably view a beneficent nonprofit hospital that has higher performance on social goals. Regulators have to find a way to navigate the often conflicting expectations of stakeholders and emerge with their legitimacy unscathed. Fixed-price regulation prevents regulators from using the price mechanism to correct such distortions to access. We explore whether regulators exhibit leniency in the form of fewer convictions of beneficent nonprofit hospitals.

Our results indicate that beneficent hospitals are less likely to be convicted for upcoding under the False Claims Act. Through differential enforcement, regulators provide hospitals with varying degrees of latitude in complying with the Act. We next examine whether, after observing the less stringent regulatory enforcement, beneficent nonprofit hospitals upcode to a greater 
extent. We find that beneficence, measured as the share of indigent patients and the provision of medical education, is positively associated with upcoding. The leniency of regulators towards beneficent nonprofit hospitals coupled with their higher upcoding permits these hospitals to obtain higher prices and partially cross-subsidize unprofitable services. Therefore, beneficent nonprofit hospitals can continue to provide unprofitable but critical services, which allow them to protect their own legitimacy, as well as contributes to the legitimacy of health care regulators among stakeholders who demand these services.

Our study makes several contributions to the literature. First, by demonstrating the interplay between regulators and regulated organizations in industries where both parties act to protect their legitimacy, our study contributes to the stream of strategic management literature that emphasizes the importance of stakeholders' influence on the interaction between regulators and organizations (e.g., Hiatt and Park, 2012). Second, while the dominant assumption in archival research in many different fields is that regulation is exogenous and uniformly imposed, our study articulates the simultaneity between regulators' and organizations' actions and thus expands our limited understanding of the complex dynamics surrounding the enforcement of regulation (Bonardi et al., 2005; Edelman and Suchman, 1997). Third, we show that in some instances regulatory judgment could potentially not be welfare reducing. In particular, in our setting, although the beneficent hospital benefits from upcoding, a portion of the increased income is likely diverted towards social welfare. Finally, by showing that upcoding might be an alternative strategy for beneficent hospitals to cover costs of unprofitable services under fixed-price reimbursement, our study contributes to the strategic management literature exploring nonprofits' strategic reactions to shifts or declines in funding (e.g., Bielefeld, 1992, 1994; McMurtry et al., 1991; Nielsen, 1986; Provan, 1987). 
Our study has several limitations. First, we focus only on three DRG families. Inclusion of more DRG families in the analysis will provide more complete results, but will substantially increase the complexity of the analysis because we need to account for interactions between families. We believe that the use of only three DRG families provides a conservative analysis because these particular families have been recognized for over a decade as being prone to upcoding. Second, although we include two measures to control for patient health status, i.e., Charlson index and mortality rate, we cannot conclusively state that every case where there is a higher proportion of DRGs in the top of the DRG family is indeed upcoding. Third, though our analysis focuses only on California, our results should be generalizable to other nonprofit hospitals not only in the United States but also in countries that use DRG-type reimbursement systems such as Australia, Germany, The Netherlands, and the United Kingdom. Finally, the U.S. health care system has recently been subject to a significant regulatory overhaul stemming from the passage of the Affordable Care Act (ACA). One of the main goals of the ACA is to lower the number of uninsured by expanding public and private insurance coverage. In particular, the Congressional Budget Office (CBO) estimates that the legislation will reduce the number of uninsured by about 30 million. However, the CBO also estimates that over 20 million residents will remain uninsured (CBO, 2012), suggesting that hospitals will continue to incur substantial costs from providing care to that population.

Our results indicate that regulators are likely to provide greater latitude to beneficent nonprofit hospitals. The weaker regulatory enforcement likely serves as a signal of the greater legitimacy enjoyed by such hospitals from regulators and community watchdogs. It would be fruitful to explore this issue in other industries. For example, research could explore whether firms that signal the importance of non-monetary goals such as environmental sustainability or 
employee learning (e.g., firms that communicate the importance of the triple bottom line) obtain some leniency from financial regulators such as the Securities and Exchange Commission (SEC).

From a social welfare perspective, upcoding helps meet some of the cost of providing indigent care or medical education. Insured individuals may perceive upcoding as a tax that helps in meeting important social needs and serves as an alternative to subsidies (which would directly or indirectly lead to higher taxes). Whether or not upcoding results in a welfare benefit or loss is an empirical question that is beyond the scope of our study. Future research could explore reasons for variations in regulatory oversight and their consequences in greater detail. 


\section{REFERENCES}

AAMC. 2013. GME Funding: How to fix the doctor shortage. https://www.aamc.org/advocacy/campaigns_and_coalitions/fixdocshortage/ (11/8/2014).

Aggarwal RK, Evans ME, Nanda D. 2011. Nonprofit Boards: Size, Performance and Managerial Incentives. Journal of Accounting and Economics 53(1-2): 466-487.

Altman EI. 1968. Financial Ratios, Discriminant Analysis and the Prediction of Corporate Bankruptcy. The Journal of Finance 23(4): 589-609.

Altman EI, Saunders A. 1997. Credit Risk Measurement: Developments over the last 20 Years. Journal of Banking \& Finance 21(11): 1721-1742.

Armstrong M, Sappington DE. 2007. Recent Developments in the Theory of Regulation. Handbook of Industrial Organization 3: 1557-1700.

Ashforth BE, Gibbs BW. 1990. The double-edge of organizational legitimation. Organization Science 1(2): 177-194.

Becker D, Kessler D, McClellan M. 2005. Detecting Medicare Abuse. Journal of Health Economics 24(1): 189-210.

Bernstein N. 2012. Hospitals fear cuts in aid for care to illegal immigrants. http://www.nytimes.com/2012/07/27/nyregion/affordable-care-act-reduces-a-fund-for-theuninsured.html?pagewanted=all\&_r=0 (11/14/2014).

Bielefeld W. 1992. Funding uncertainty and nonprofit strategies in the 1980s. Nonprofit Management and Leadership 2(4): 381-401.

Bielefeld W. 1994. What affects nonprofit survival? Nonprofit Management and Leadership 5(1): 19-36.

Blount LL, Gold RS. 1999. False Claim Allegations Over Unspecified vs. Other Specified Bacteria: Analysis of DRG 79 Issues. Healthcare Management Advisors.

Bonardi J-P, Hillman AJ, Keim GD. 2005. The Attractiveness of Political Markets: Implications for Firm Strategy. The Academy of Management Review 30(2): 397-413.

Bonardi JP. 2004. Global and political strategies in deregulated industries: The asymmetric behaviors of former monopolies. Strategic Management Journal 25(2): 101-120.

Breusch TS, Pagan AR. 1980. The Lagrange Multiplier Test and Its Applications to Model Specification in Econometrics. The Review of Economic Studies 47(1): 239-253.

Brickley JA, Van Horn RL. 2002. Managerial Incentives in Nonprofit Organizations: Evidence from Hospitals. The Journal of Law and Economics 45: 227-249.

Brown LD. 1992. Political evolution of federal health care regulation. Health Affairs 11(4): 1737.

Carpenter DP. 2004. Protection without Capture: Product Approval by a Politically Responsive, Learning Regulator. The American Political Science Review 98(4): 613-631.

Carreyrou J, Martinez B. 2008. Nonprofit Hospitals, Once For the Poor, Strike It Rich. In The Wall Street Journal.

CBO. 2012. Estimates for the insurance coverage provisions of the Affordable Care Act updated for the recent Supreme Court decision. http://www.cbo.gov/sites/default/files/cbofiles/attachments/43472-07-24-2012CoverageEstimates.pdf.

Charlson ME, Pompei P, Ales KL, MacKenzie CR. 1987. A New Method of Classifying Prognostic Comorbidity in Longitudinal Studies: Development and Validation. Journal of Chronic Diseases 40(5): 373-383. 
CHCS. 2010. The future of U.S. charity care programs: Implications of health reform http://www.academyhealth.org/files/publications/FutureofCharityCarePrograms.pdf $(12 / 14 / 2014)$.

Chen HF, Bazzoli GJ, Hsieh HM. 2009. Hospital Financial Conditions and the Provision of Unprofitable Services. Atlantic Economic Journal 37(3): 259-277.

Clement JP, Smith DG, Wheeler JR. 1994. What do we want and what do we get from Not-forProfit Hospitals? Hospital \& Health Services Administration 39(2): 159-178.

CMS. 2004. Fiscal Year 2004 Improper Medicare Fee-For-Service Payment Report.

CMS. 2005a. CMS administrator Dr. McClellan speaks before the national governors' association. http://www.cms.gov/Newsroom/MediaReleaseDatabase/Fact-Sheets/2005-FactSheets-Items/2005-05-02.html (6/21/2014).

CMS. 2005b. DRG Relative Weights.

CMS. 2010. Acute Care Hospital Inpatient Prospective Payment System

CMS. 2013. CMS Strategy: The Road Forward. http://www.cms.gov/About-CMS/AgencyInformation/CMS-Strategy/Downloads/CMS-Strategy.pdf.

Congress. 2010. Subcommittee hearing: "Cutting Waste, Fraud, and Abuse in Medicare and Medicaid".

http://democrats.energycommerce.house.gov/documents/20100920/Health.2010.9.20.pdf.

Congress US. 1981. Hearings on Medicaid Cutbacks on Infant Care.

Cooper RA. 2007. It's time to address the problem of physician shortages: graduate medical education is the key. Annals of Surgery 246(4): 527-534.

Covaleski MA, Dirsmith MW, Michelman JE. 1993. An Institutional Theory Perspective on the DRG Framework, Case-mix Accounting Systems and Health-care Organizations. Accounting, Organizations and Society 18(1): 65-80.

Crennen C. 2013. Major Cases Involving Upcoding by Hospitals. http://medicarefalseclaims.com/?page_id=358 (6/12/2013).

Dafny L. 2005. How Do Hospitals Respond to Price Changes? The American Economic Review 95(5): 1525-1547.

Deephouse DL, Suchman MC. 2008. Legitimacy in organizational institutionalism. In The Sage Handbook of Organizational Institutionalism. Greenwood RC, Suddaby OR, Sahlin K (eds.), Sage: Thousand Oaks, CA.

Degeorge F, Patel J, Zeckhauser R. 1999. Earnings Management to Exceed Thresholds. Journal of Business 72(1): 1-33.

Delmas M, Toffel MW. 2004. Stakeholders and environmental management practices: an institutional framework. Business Strategy and the Environment 13(4): 209-222.

Demski JS, Sappington DE. 1987. Hierarchical Regulatory Control. The Rand Journal of Economics: 369-383.

DiMaggio PJ, Powell WW. 1983. The iron cage revisited: Institutional isomorphism and collective rationality in organizational fields. American Sociological Review: 147-160.

DOJ. 2012. The False Claims Act: A Primer. http://www.justice.gov/civil/docs_forms/CFRAUDS_FCA_Primer.pdf.

Dowling J, Pfeffer J. 1975. Organizational legitimacy: Social values and organizational behavior. Pacific Sociological Review: 122-136.

Dranove D. 1988. Pricing by non-profit institutions: the case of hospital cost-shifting. Journal of Health Economics 7(1): 47-57. 
Eckholm E. 2006. Hospitals try free basic care for uninsured. http://www.nytimes.com/2006/10/25/health/25insure.html?pagewanted=all\&_r=0 $\quad(11 / 11$ 2014).

Edelman LB. 1992. Legal ambiguity and symbolic structures: Organizational mediation of civil rights law. American Journal of Sociology 97: 1531-1576.

Edelman LB, Suchman MC. 1997. The legal environments of organizations. Annual Review of Sociology 23: 479-515.

Edelman LB, Uggen C, Erlanger HS. 1999. The endogeneity of legal populations: Grievance procedures or rational myth. American Journal of Sociology 105: 406-454.

Eldenburg L, Gunny KA, Hee KW, Soderstrom N. 2011. Earnings Management Using Real Activities: Evidence from Nonprofit Hospitals. The Accounting Review 86(5): 1605-1630.

Eldenburg L, Krishnan R. 2003. Public versus Private Governance: A Study of Incentives and Operational Performance. Journal of Accounting and Economics 35(3): 377-404.

Folland S, Goodman AC, Stano M. 1997. The Economics of Health and Health Care. Prentice Hall: New Jersey.

Frank RG, Salkever DS. 1991. The supply of charity services by nonprofit hospitals: Motives and market structure. The Rand Journal of Economics: 430-445.

Frank RG, Salkever DS. 1994. Nonprofit Organization in the Health Sector. The Journal of Economic Perspectives 8(4): 129-144.

Freeman RE. 1984. Strategic management: A stakeholder approach. Prentice Hall.

Gallup. 2014. U.S. Uninsured rate dipped back down at the end of 2013. http://www.gallup.com/poll/166895/uninsured-rate-dipped-back-down-end-2013.aspx （11/8 2014).

GAO. 2000. Medicare Improper Payments.

GAO. 2013. High-risk series - An update.

Gruber J. 1994. The effect of competitive pressure on charity: Hospital responses to price shopping in California. Journal of Health Economics 13(2): 183-211.

Hadley J, Holahan J, Coughlin T, Miller D. 2008. Covering the uninsured in 2008: current costs, sources of payment, and incremental costs. Health Affairs 27(5): 399-415.

Harris JE. 1979. Pricing rules for hospitals. The Bell Journal of Economics 10: 224-243.

Hausman JA. 1978. Specification Tests in Econometrics. Econometrica: Journal of the Econometric Society 46(6): 1251-1271.

HHS. 2001. HHS strategic goals and objectives - FY 2001. http://aspe.hhs.gov/hhsplan/2001/index.shtml (11/14/2014).

HHS. 2013. FY 2013 - Agency Financial Report.

HHS. 2014a. HHS Strategic Plan. http://www.hhs.gov/strategic-plan/goal1.html (11/14/2014).

HHS. 2014b. Strategic goal 1: Strengthen health care. http://www.hhs.gov/strategicplan/goal1.html\#obj_e (12/14/2014).

Hiatt S, Park S. 2012. Lords of the harvest: Third-party influence and regulatory approval of genetically modified organisms. Academy of Management Journal.

Hillman A, Keim G. 1995. International Variation in the Business-Government Interface: Institutional and Organizational Considerations. The Academy of Management Review 20(1): 193-214.

Hoerger TJ. 1991. Profit Variability in For-Profit and Not-For-Profit Hospitals. Journal of Health Economics 10(3): 259-289. 
Holburn GL, Zelner BA. 2010. Political capabilities, policy risk, and international investment strategy: Evidence from the global electric power generation industry. Strategic Management Journal 31(12): 1290-1315.

Hsia RYJ, Shen YC. 2011. Rising Closures Of Hospital Trauma Centers Disproportionately Burden Vulnerable Populations. Health Affairs 30(10): 1912-1920.

Iglehart JK. 2009. Doing more with less: a conversation with Kerry Weems. Health Affairs 28(4): 688-696.

Jia N. 2013. Are Collective and Private Political Actions Substitutes or Complements? Empirical Evidence from China's Private Sector. Strategic Management Journal.

Kane NM, Wubbenhorst WH. 2000. Alternative funding policies for the uninsured: exploring the value of hospital tax exemption. Milbank Quarterly 78(2): 185-212.

Kearns KP. 1994. The Strategic Management of Accountability in Nonprofit Organizations: An Analytical Framework. Public Administration Review 54(2): 185-192.

King BG, Felin T, Whetten DA. 2010. Finding the Organization in Organizational Theory: A Meta-Theory of the Organization as a Social Actor. Organization Science 21(1): 290-305.

Klein CC, Sweeney G. 1999. Regulator Preferences and Utility Prices: Evidence from Natural Gas Distribution Utilities. Energy Economics 21(1): 1-15.

Krishnan RA, Joshi S, Krishnan H. 2004. The Influence of Mergers on Firms' Product-Mix Strategies. Strategic Management Journal 25(6): 587-611.

Kwoka Jr JE. 1985. The Herfindahl Index in Theory and Practice. Antitrust Bull 30: 915-948.

Laffont J-J, Tirole J. 1991. The politics of government decision-making: A theory of regulatory capture. The Quarterly Journal of Economics 106(4): 1089-1127.

Lambert RA, Larcker DF. 1995. The Prospective Payment System, Hospital Efficiency, and Compensation Contracts for Senior-Level Hospital Administrators. Journal of Accounting and Public Policy 14(1): 1-31.

Leone AJ, Van Horn RL. 2005. How do Nonprofit Hospitals Manage Earnings? Journal of Health Economics 24(4): 815-837.

Lewin T. 1997. Hospitals serving the poor struggle to retain patients. http://www.nytimes.com/1997/09/03/us/hospitals-serving-the-poor-struggle-to-retainpatients.html (11/14 2014).

McMurtry SL, Netting FE, Kettner PM. 1991. How nonprofits adapt to a stringent environment. Nonprofit Management and Leadership 1(3): 235-252.

Meyer JW, Rowan B. 1977. Institutionalized Organizations: Formal Structure as Myth and Ceremony. American Journal of Sociology 83(2): 340-363.

Morrisey MA, Wedig GJ, Hassan M. 1996. Do Nonprofit Hospitals Pay Their Way? Health Affairs 15(4): 132-144.

Naughton MC. 1989. Regulatory Preferences and Two-Part Tariffs: The Case of Electricity. Southern Economic Journal 55(3): 743-758.

Nielsen RP. 1986. Piggybacking Strategies for Nonprofits: A Shared Costs Approach. Strategic Management Journal 7(3): 201-215.

OIG H. 1998. Using Software to Detect Upcoding of Hospital Bills.

OIG H. 2001a. Improper Fiscal Year 2000 Medicare Fee-For-Service Payments.

OIG H. 2001b. Medicare Hospital Prospective Payment System: How DRG Rates Are Calculated and Updated.

Okten C, Weisbrod BA. 2000. Determinants of Donations in Private Nonprofit Markets. Journal of Public Economics 75(2): 255-272.

Pear R. 1990. Tax Exemptions of Nonprofit Hospitals Scrutinized. In The New York Times. 
Pear R. 2006. Nonprofit Hospitals Face Scrutiny Over Practices. In The New York Times.

Peltzman S. 1976. Toward a more general Theory of Regulation. Journal of Law and Economics 19: 211-240.

Pfeffer J. 1981. Management as symbolic action: The creation and maintenance of organizational paradigms. Research in Organizational Behavior 3(1): 1-52.

Provan KG. 1987. Environmental and Organizational Predictors of Adoption of Cost Containment Policies in Hospitals. The Academy of Management Journal 30(2): 219-239.

Reinhardt UE. 2006. The Pricing of US Hospital Services: Chaos behind a Veil of Secrecy. Health Affairs 25(1): 57-69.

Rose-Ackerman S. 1996. Altruism, Nonprofits, and Economic Theory. Journal of Economic Literature 34(2): 701-728.

Ruef M, Scott WR. 1998. A Multidimensional Model of Organizational Legitimacy: Hospital Survival in Changing Institutional Environments. Administrative Science Quarterly 43(4): 877-904.

Sanders B. 2013. Primary Care Access - 30 Million New Patients and 11 Months to Go: Who Will Provide Their Primary Care?Subcommittee on Primary Health and Aging - U.S. Senate Committee on Health E, Labor \& Pensions (ed.).

Sapolsky HM. 1986. Prospective Payment in Perspective. Journal of Health Politics, Policy and Law 11(4): 633-645.

Schuck PH. 1986. Designing hospital care subsidies for the poor. In Uncompensated hospital care rights and responsibilities. Sloan FA, Blumstein JF, Perrin JM (eds.), John Hopkins University Press: Baltimore.

Scott WR. 2001. Institutions and Organizations. Sage: Thousand Oaks, CA.

Shleifer A, Vishny RW. 1994. Politicians and firms. The Quarterly Journal of Economics: 9951025.

Silverman E, Skinner J. 2004. Medicare Upcoding and Hospital Ownership. Journal of Health Economics 23(2): 369-389.

Sloan RG. 1993. Accounting Earnings and Top Executive Compensation. Journal of Accounting and Economics 16(1-3): 55-100.

Soderstrom N. 1993. Hospital Behavior under Medicare Incentives. Journal of Accounting and Public Policy 12(2): 155-185.

Steinbusch PJM, Oostenbrink JB, Zuurbier JJ, Schaepkens FJM. 2007. The Risk of Upcoding in Casemix Systems: A Comparative Study. Health Policy 81(2-3): 289-299.

Stewart CS, Weaver C. 2014. Probes of overbilling run into political pressure. In The Wall Street Journal.

Stigler GJ. 1971. The Theory of Economic Regulation. The Bell Journal of Economics and Management Science 2(1): 3-21.

Suchman MC. 1995. Managing Legitimacy: Strategic and Institutional Approaches. The Academy of Management Review 20(3): 571-610.

TAF. 2007. Fraud Statistics - 1986-2007.

Torio CM, Andrews RM. 2013. National Inpatient Hospital Costs: The Most Expensive Conditions by Payer in 2011.

Weingast BR. 1984. The congressional-bureaucratic system: a principal agent perspective (with applications to the SEC). Public Choice 44(1): 147-191.

Weingast BR, Moran MJ. 1983. Bureaucratic discretion or congressional control? Regulatory policymaking by the Federal Trade Commission. The Journal of Political Economy 5: 765800. 
Weisbrod BA. 1977. The Voluntary Nonprofit Sector. Lexington Books Massachusetts.

Weisbrod BA. 1988. The Nonprofit Economy. Harvard University Press: Cambridge.

Wennberg JE, Cooper MM. 1999. The Quality of Medical Care in the United States: A Report on the Medicare Program. The Dartmouth Atlas of Health Care. American Hospital Association Press: Chicago, IL.

Wooldridge JM. 2002. Econometric Analysis of Cross Section and Panel Data (2nd ed.). The MIT Press: Boston.

Yermack D. 1996. Higher Market Valuation of Companies with a Small Board of Directors. Journal of Financial Economics 40(2): 185-211.

Zellner A. 1962. An Efficient Method of Estimating Seemingly Unrelated Regressions and Tests for Aggregation Bias. Journal of the American Statistical Association 57(298): 348-368. 
Table 1. Overview of DRG monetary incentives

Panel A: Description of DRG groups

\begin{tabular}{|c|c|c|c|c|}
\hline $\begin{array}{c}\text { Incentive } \\
\text { Classification of } \\
\text { DRG Family }^{\mathbf{a}}\end{array}$ & $\begin{array}{c}\text { DRG } \\
\text { Number } \\
\text { (based on } \\
\text { ICD-9-CM) }\end{array}$ & Description & $\begin{array}{c}\text { DRG } \\
\text { Weight }^{\mathrm{c}}\end{array}$ & $\begin{array}{c}\text { Revenue } \\
\text { Estimate }^{d}(\$)\end{array}$ \\
\hline \multirow{3}{*}{$\begin{array}{l}\text { High Incentives } \\
\text { Family (General } \\
\text { Respiratory } \\
\text { Ailments) }\end{array}$} & 79 (TOP) & $\begin{array}{l}\text { Respiratory infections and inflammations with } \\
\text { complicating and comorbidity factors (cc) }\end{array}$ & 1.59 & $8,188.50$ \\
\hline & 80 & Respiratory infections without (w/o) cc & 0.85 & $4,377.50$ \\
\hline & $\begin{array}{l}89 \\
90\end{array}$ & $\begin{array}{l}\text { Pneumonia with (w) cc } \\
\text { Pneumonia w/o cc }\end{array}$ & $\begin{array}{l}1.05 \\
0.62\end{array}$ & $\begin{array}{l}5,407.50 \\
3,193.00\end{array}$ \\
\hline \multirow{9}{*}{$\begin{array}{c}\text { Medium } \\
\text { Incentives Family } \\
\text { (Circulatory } \\
\text { System } \\
\text { Disorders) }\end{array}$} & 132 & Atherosclerosis w cc & 0.64 & $3,296.00$ \\
\hline & 133 & Atherosclerosis w/o cc & 0.54 & $2,781.00$ \\
\hline & 138 & $\begin{array}{l}\text { Cardiac arrhythmia and conduction disorders w } \\
\text { cC }\end{array}$ & 0.84 & $4,326.00$ \\
\hline & 139 & $\begin{array}{l}\text { Cardiac arrhythmia and conduction disorders } \\
\text { w/o cc }\end{array}$ & 0.52 & $2,678.00$ \\
\hline & 140 & Angina Pectoris & 0.53 & $2,729.50$ \\
\hline & 141 & Syncope and collapse w cc & 0.76 & $3,914.00$ \\
\hline & 142 & Syncope and collapse w/o cc & 0.59 & $3,038.50$ \\
\hline & 144 (TOP) & Other circulatory system diagnoses w cc & 1.25 & $6,437.50$ \\
\hline & 145 & Other circulatory system diagnoses w/o cc & 0.59 & $3,038.50$ \\
\hline \multirow{4}{*}{$\begin{array}{l}\text { Low Incentives } \\
\text { Family (Diabetes } \\
\text { and } \\
\text { Nutritional/Meta } \\
\text { bolic Disorders) }\end{array}$} & 182 & $\begin{array}{l}\text { Esophagitis, gastroenteritis and miscellaneous } \\
\text { digestive disorders age }>17 \mathrm{w} \mathrm{cc}\end{array}$ & 0.79 & $4,068.50$ \\
\hline & 294 & Diabetes age $>35$ & 0.78 & $4,017.00$ \\
\hline & 296 (TOP) & $\begin{array}{l}\text { Nutritional and miscellaneous metabolic } \\
\text { disorders age }>17 \text { w cc }\end{array}$ & 0.84 & $4,326.00$ \\
\hline & 297 & $\begin{array}{l}\text { Nutritional and miscellaneous metabolic } \\
\text { disorders age }>17 \text { w/o cc }\end{array}$ & 0.50 & $2,575.00$ \\
\hline
\end{tabular}

Notes to Table 1, Panel A:

${ }^{a}$ Based on the financial benefit from upcoding from one of the lower-revenue DRG numbers to the highest-revenue DRG number.

b "TOP” refers to the DRG that has the highest revenue in the DRG family. ICD-9-CM refers to the International Classification of Diseases, Ninth Revision, Clinical Modification. This classification is used to assign diagnostic and procedure codes associated with inpatient, outpatient, and physician office utilization in the United States.

${ }^{c}$ Refers to the weight assigned by CMS to each DRG. The weight reflects the average level of resources for an average Medicare patient belonging to the DRG, relative to the average level of resources for all Medicare patients. The weights are intended to account for cost variations between different types of treatments. More expensive conditions are assigned higher DRG weights.

${ }^{\mathrm{d}}$ Refers to the revenue estimate per DRG in dollar calculated as the DRG weight times the average base rate for the year 2005 for a DRG weight of $1(\$ 5,150)$. 
Panel B: Monetary incentives per DRG groups

\begin{tabular}{|c|c|c|c|c|c|c|}
\hline $\begin{array}{c}\text { Incentive } \\
\text { Classification of } \\
\text { DRG Family }\end{array}$ & $\begin{array}{c}\text { Difference } \\
\text { between Top } \\
\text { DRG and } \\
\text { Family } \\
\text { Average }^{\mathrm{a}}\end{array}$ & $\begin{array}{c}\text { Average } \\
\text { Payment } \\
\text { Incentive } \\
(\$)^{\mathbf{b}}\end{array}$ & $\begin{array}{c}\text { Max. } \\
\text { Difference }^{c}\end{array}$ & $\begin{array}{c}\text { Max. } \\
\text { Payment } \\
\text { Incentive } \\
(\$)^{d}\end{array}$ & $\begin{array}{c}\text { Min. } \\
\text { Difference }\end{array}$ & $\begin{array}{c}\text { Min. } \\
\text { Payment } \\
\text { Incentive } \\
\quad(\$)^{f}\end{array}$ \\
\hline $\begin{array}{l}\text { High Incentives } \\
\text { (General } \\
\text { Respiratory } \\
\text { Ailments) } \\
\end{array}$ & 0.75 & $3,862.50$ & 0.97 & 4,995.50 & 0.54 & $2,781.00$ \\
\hline $\begin{array}{c}\text { Medium } \\
\text { Incentives } \\
\text { (Circulatory } \\
\text { system disorders) }\end{array}$ & 0.62 & 3,212.31 & 0.73 & $3,759.50$ & 0.41 & $2,111.50$ \\
\hline $\begin{array}{l}\text { Low Incentives } \\
\text { (Diabetes and } \\
\text { nutritional/metab } \\
\text { olic disorders) }\end{array}$ & 0.15 & 772.50 & 0.34 & $1,751.00$ & 0.06 & 309.00 \\
\hline \multicolumn{7}{|c|}{$\begin{array}{l}\text { Notes to Table 1, Panel B: } \\
\text { a Computed as the difference between the TOP DRG weight and the average DRG weight of the other DRGs in the } \\
\text { family. } \\
\text { b Computed as the average difference between TOP DRG weight and family average weight in dollars, i.e., } \\
\text { difference in weight times the average base rate for the year } 2005 \text { for a DRG weight of } 1(\$ 5,150) \text {. } \\
\text { c Computed as the difference between the TOP DRG weight and the lowest DRG weight per family. } \\
\text { d Computed as the maximum difference between TOP DRG weight and lowest DRG weight per family in dollar, i.e., } \\
\text { difference in weight times the average base rate for the year } 2005 \text { for a DRG weight of } 1 \text { ( } \$ 5,150) \text {. } \\
\text { e Computed as the difference between the TOP DRG weight and the second highest DRG weight per family. } \\
\text { f Computed as the minimum difference between TOP DRG weight and second highest DRG weight per family in } \\
\text { dollar, i.e., difference in weight times the average base rate for the year } 2005 \text { for a DRG weight of } 1(\$ 5,150) \text {. }\end{array}$} \\
\hline
\end{tabular}


Panel C: Overview of discharges in DRG families per hospital and year ${ }^{\mathrm{a}}$

\begin{tabular}{|c|c|c|c|c|c|c|c|c|}
\hline Year & $\begin{array}{c}\text { Mean } \\
\text { Number } \\
\text { of } \\
\text { Discharge } \\
\text { s DRG } \\
79 \\
\text { Familyb }\end{array}$ & $\begin{array}{c}\text { DRG } 79 \\
\text { Family } \\
\text { Discharge } \\
\mathrm{s} \text { in \% of } \\
\text { Total } \\
\text { Discharge } \\
\mathrm{s}\end{array}$ & $\begin{array}{c}\text { Mean } \\
\text { Number } \\
\text { of } \\
\text { Discharge } \\
\text { s DRG } \\
144 \\
\text { Family }^{\text {b }}\end{array}$ & $\begin{array}{c}\text { DRG } 144 \\
\text { Family } \\
\text { Discharge } \\
\mathrm{s} \text { in \% of } \\
\text { Total } \\
\text { Discharge } \\
\mathrm{s}\end{array}$ & $\begin{array}{c}\text { Mean } \\
\text { Number } \\
\text { of } \\
\text { Discharge } \\
\text { s DRG } \\
296 \\
\text { Family }\end{array}$ & $\begin{array}{c}\text { DRG } 296 \\
\text { Family } \\
\text { Discharge } \\
\mathrm{s} \text { in \% of } \\
\text { Total } \\
\text { Discharge } \\
\mathrm{s}\end{array}$ & $\begin{array}{c}\text { Mean } \\
\text { Number } \\
\text { of } \\
\text { Discharge } \\
\text { s in all } \\
\text { three } \\
\text { DRG } \\
\text { Families }\end{array}$ & $\begin{array}{l}\text { All three } \\
\text { DRG } \\
\text { Families } \\
\text { Discharges } \\
\text { in \% of } \\
\text { Total } \\
\text { Discharges }\end{array}$ \\
\hline 1996 & 313 & 4.3 & 308 & 4.0 & 238 & 3.1 & 859 & 11.4 \\
\hline 1997 & 343 & 4.5 & 324 & 4.1 & 255 & 3.1 & 922 & 11.7 \\
\hline 1998 & 345 & 4.4 & 320 & 4.0 & 263 & 3.2 & 928 & 11.6 \\
\hline 1999 & 377 & 4.9 & 329 & 4.0 & 283 & 3.4 & 989 & 12.3 \\
\hline 2000 & 341 & 4.3 & 338 & 3.9 & 298 & 3.4 & 977 & 11.6 \\
\hline 2001 & 352 & 4.3 & 333 & 3.7 & 306 & 3.5 & 991 & 11.5 \\
\hline 2002 & 339 & 4.4 & 321 & 3.8 & 321 & 3.8 & 981 & 12 \\
\hline 2003 & 374 & 4.4 & 324 & 3.5 & 326 & 3.6 & 1024 & 11.5 \\
\hline 2004 & 336 & 3.9 & 335 & 3.4 & 337 & 3.5 & 1008 & 10.8 \\
\hline 2005 & 378 & 4.3 & 337 & 3.4 & 343 & 3.6 & 1058 & 11.3 \\
\hline 2006 & 339 & 3.8 & 338 & 3.4 & 371 & 3.8 & 1048 & 11 \\
\hline 2007 & 318 & 3.5 & 337 & 3.3 & 347 & 3.5 & 1002 & 10.3 \\
\hline
\end{tabular}

Notes to Table 1, Panel C:

${ }^{a}$ The data are obtained from the Office of Statewide Health Planning and Development (OSHPD).

Table 2. Overview of convicted hospitals per year ${ }^{\mathrm{a}}$

\begin{tabular}{cccc}
\hline Year & Number of Hospitals $^{\mathbf{b}}$ & Number of convicted Hospitals & \% of Sample \\
\hline 1996 & 186 & 21 & 11.2 \\
1997 & 186 & 22 & 11.8 \\
1998 & 185 & 24 & 12.9 \\
\hline & 557 & 67 & 12.0 \\
\hline
\end{tabular}

Notes to Table 2:

a Data from the False Claim Act settlement agreements of the U.S. Department of Justice. The data relate to convictions that occurred after 1998 for upcoding conducted between 1996 and 1998.

${ }^{\mathrm{b}}$ Number of all California nonprofit general acute care hospitals per year. The data are obtained from the Office of Statewide Health Planning and Development (OSHPD). 
Table 3. Overview of variables

\begin{tabular}{|c|c|}
\hline Variable & Definition \\
\hline \multicolumn{2}{|l|}{ Dependent Variables } \\
\hline Conviction Dummy & $\begin{array}{l}\text { Continuous variable between } 0 \text { and } 1 \text {; calculated as the number of } \\
\text { patients in the TOP DRG divided by the total number of patients in the } \\
\text { DRG group. } \\
1 \text { in the years a hospital has conducted upcoding as reported in the } \\
\text { convictions for upcoding under the False Claims Act, and zero } \\
\text { otherwise. }\end{array}$ \\
\hline \multicolumn{2}{|l|}{ Predictor Variables } \\
\hline $\begin{array}{l}\text { Percentage of Indigents } \\
\text { Resident-to-Bed Ratio }\end{array}$ & $\begin{array}{l}\text { Indigent patient days as percentage of total patient days. } \\
\text { Number of residents trained per inpatient bed. }\end{array}$ \\
\hline \multicolumn{2}{|l|}{ Patient-Level Control Variables } \\
\hline Charlson Index for Indigents & $\begin{array}{l}\text { Index that captures the weighted average patient's health status within a } \\
\text { DRG group; score combines assigned weights }(1,2,3,6) \text { based on } \\
\text { comorbidity (e.g., weight } 1 \text { for diabetes, weight } 6 \text { for metastatic solid } \\
\text { tumor) and assigned weights ( } 0 \text { to } 5) \text { based on age }(1 \text { point for each } \\
\text { decade starting at } 50 \text {, e.g., } 40 \text { to } 49=0 ; 50 \text { to } 59=1) \text {; weighting is } \\
\text { based on number of patients per DRG. } \\
\text { Index that captures the weighted average indigent patient's health status } \\
\text { within a DRG group; calculated in the same manner as the Charlson } \\
\text { index. } \\
\text { Rate that captures the share of people that died within a DRG group } \\
\text { during the stay at the hospital. }\end{array}$ \\
\hline \multicolumn{2}{|l|}{ Hospital-Level Control Variables } \\
\hline Benchmark Dummy & $\begin{array}{l}1 \text { if the hospital has just met the zero-earnings benchmark (i.e., } 0 \text { to } 0.02 \\
\text { based on } 2^{*} \mathrm{IQR}^{*} \mathrm{n}^{-1 / 3} \text { ), } 0 \text { otherwise. }\end{array}$ \\
\hline $\begin{array}{l}\text { P4P Dummy } \\
\text { (First lag of) ROA }\end{array}$ & $\begin{array}{l}1 \text { if positive P4P incentives exist, } 0 \text { otherwise. } \\
\text { (First lag of) net income divided by total assets. }\end{array}$ \\
\hline Z-Score & $\begin{array}{l}1.2 \text { times working capital divided by total assets plus } 1.4 \text { times retained } \\
\text { earnings divided by total assets plus } 3.3 \text { times earnings before interest } \\
\text { and taxes divided by total assets plus } 0.6 \text { times total equity divided by } \\
\text { total liabilities plus revenue divided by total assets. }\end{array}$ \\
\hline Percentage of Medicare & Medicare patient days as percentage of total patient days. \\
\hline Case Mix Index (CMI) & Case mix index of hospital. \\
\hline Log Discharges & Natural logarithm of number of discharges. \\
\hline Log Boardsize & Natural logarithm of number of board members. \\
\hline System Hospital Dummy & 1 if the hospital belongs to a system, 0 otherwise. \\
\hline Rural Hospital Dummy & 1 if the hospital is located in a rural area, 0 otherwise. \\
\hline Church Dummy & 1 if the hospital is church-owned, 0 otherwise. \\
\hline \multicolumn{2}{|c|}{ Hospital-Market-Level Control Variables } \\
\hline Log Median Household Income & $\begin{array}{l}\text { Herfindahl-Hirschman Index; sum of squared market shares per local } \\
\text { market. } \\
\text { Natural logarithm of the median household income per hospital service } \\
\text { area. }\end{array}$ \\
\hline
\end{tabular}


Table 4. Descriptive statistics for years 1996 to $1998(\mathrm{~N}=557)^{\mathrm{a}}$

\begin{tabular}{|c|c|c|c|c|c|c|c|}
\hline Variable & Mean & Std. & Min. & Q1 & Median & Q3 & Max. \\
\hline \multicolumn{8}{|l|}{ Dependent Variables } \\
\hline DRG Ratio 79 & 0.281 & 0.117 & 0.023 & 0.186 & 0.256 & 0.337 & 0.631 \\
\hline DRG Ratio 144 & 0.122 & 0.065 & 0.007 & 0.076 & 0.114 & 0.158 & 0.359 \\
\hline DRG Ratio 296 & 0.357 & 0.076 & 0.146 & 0.309 & 0.353 & 0.405 & 0.548 \\
\hline \multicolumn{8}{|l|}{ Predictor Variables } \\
\hline \%Indigents & 1.238 & 2.021 & 0 & 0 & 0.299 & 1.837 & 10.227 \\
\hline Resident-to-Bed Ratio & 0.045 & 0.124 & 0 & 0 & 0 & 0 & 0.901 \\
\hline \multicolumn{8}{|c|}{ Patient-Level Control Variables } \\
\hline Charlson Index 79 & 4.136 & 0.461 & 2.438 & 3.896 & 4.200 & 4.445 & 4.989 \\
\hline Charlson Index Ind. 79 & 0.490 & 0.975 & 0 & 0 & 0 & 0.667 & 5.000 \\
\hline Mortality Rate 79 & 0.067 & 0.024 & 0 & 0.052 & 0.066 & 0.081 & 0.132 \\
\hline Charlson Index 144 & 3.276 & 0.409 & 2.010 & 3.036 & 3.307 & 3.564 & 4.154 \\
\hline Charlson Index Ind. 144 & 0.682 & 1.110 & 0 & 0 & 0 & 0.481 & 4.333 \\
\hline Mortality Rate 144 & 0.015 & 0.010 & 0 & 0.008 & 0.014 & 0.020 & 0.052 \\
\hline Charlson Index 296 & 3.362 & 0.534 & 1.782 & 3.074 & 3.404 & 3.700 & 4.525 \\
\hline Charlson Index Ind. 296 & 0.394 & 0.845 & 0 & 0 & 0 & 0.481 & 5.000 \\
\hline Mortality Rate 296 & 0.016 & 0.012 & 0 & 0.007 & 0.014 & 0.023 & 0.062 \\
\hline \multicolumn{8}{|c|}{ Hospital-Level Control Variables } \\
\hline Benchmark Dummy & 0.114 & 0.318 & 0 & 0 & 0 & 0 & 1 \\
\hline P4P Dummy & 0.436 & 0.496 & 0 & 0 & 0 & 1 & 1 \\
\hline Revenues in 000s & 231,995 & 221,713 & 8,853 & 79,873 & 168,142 & 312,675 & $1,254,061$ \\
\hline Net Income in 000s & 4,771 & 11,823 & $-16,861$ & -494 & 1,909 & 6,626 & 67,563 \\
\hline Total Assets in 000s & 120,112 & 129,190 & 2,159 & 33,523 & 78,352 & 166,459 & 718,047 \\
\hline $\mathrm{ROA}_{\mathrm{t}-1}$ & 0.031 & 0.092 & -0.290 & -0.002 & 0.034 & 0.070 & 0.341 \\
\hline Zscore & 3.301 & 1.946 & -0.649 & 2.303 & 2.946 & 3.653 & 14.386 \\
\hline \%Medicare & 40.943 & 13.816 & 7.849 & 31.405 & 41.008 & 51.680 & 71.963 \\
\hline CMI & 1.084 & 0.192 & 0.740 & 0.950 & 1.050 & 1.190 & 1.750 \\
\hline Teaching Dummy & 0.225 & 0.418 & 0 & 0 & 0 & 0 & 1 \\
\hline Discharges & 9,389 & 6,624 & 307 & 4,064 & 8,079 & 13,306 & 30,653 \\
\hline Log Discharges & 8.834 & 0.895 & 5.740 & 8.310 & 8.997 & 9.496 & 10.326 \\
\hline Boardsize & 14.71 & 5.19 & 2 & 12 & 15 & 18 & 29 \\
\hline Log Boardsize & 2.604 & 0.466 & 0.693 & 2.485 & 2.708 & 2.890 & 3.367 \\
\hline System Dummy & 0.497 & 0.500 & 0 & 0 & 0 & 1 & 1 \\
\hline Rural Dummy & 0.139 & 0.345 & 0 & 0 & 0 & 0 & 1 \\
\hline Church Dummy & 0.224 & 0.417 & 0 & 0 & 0 & 0 & 1 \\
\hline \multicolumn{8}{|c|}{ Hospital-Market-Level Control Variables } \\
\hline HHI & 0.195 & 0.235 & 0.015 & 0.040 & 0.117 & 0.273 & 1 \\
\hline $\begin{array}{l}\text { Median Household } \\
\text { Income in \$ }\end{array}$ & 39,460 & 7,826 & 27,885 & 33,828 & 37,655 & 44,998 & 61,257 \\
\hline $\begin{array}{l}\text { Log Median } \\
\text { Household Income }\end{array}$ & 10.565 & 0.190 & 10.236 & 10.429 & 10.536 & 10.714 & 11.023 \\
\hline
\end{tabular}


Table 5. Descriptive statistics for years 1999 to $2007(\mathrm{~N}=1,447)^{\mathrm{a}}$

\begin{tabular}{|c|c|c|c|c|c|c|c|}
\hline Variable & Mean & Std. & Min. & Q1 & Median & Q3 & Max. \\
\hline \multicolumn{8}{|l|}{ Dependent Variables } \\
\hline DRG Ratio 79 & 0.228 & 0.093 & 0.022 & 0.167 & 0.216 & 0.282 & 0.541 \\
\hline DRG Ratio 144 & 0.146 & 0.078 & 0 & 0.094 & 0.134 & 0.182 & 0.423 \\
\hline DRG Ratio 296 & 0.337 & 0.069 & 0.167 & 0.292 & 0.337 & 0.379 & 0.547 \\
\hline \multicolumn{8}{|l|}{ Predictor Variables } \\
\hline \%Indigents & 1.392 & 1.902 & 0 & 0 & 0.381 & 2.271 & 7.142 \\
\hline Resident-to-Bed Ratio & 0.047 & 0.132 & 0 & 0 & 0 & 0 & 0.680 \\
\hline \multicolumn{8}{|c|}{ Patient-Level Control Variables } \\
\hline Charlson Index 79 & 4.282 & 0.453 & 2.739 & 4.025 & 4.322 & 4.601 & 5.221 \\
\hline Charlson Index Ind. 79 & 0.232 & 0.715 & 0 & 0 & 0 & 0 & 4.000 \\
\hline Mortality Rate 79 & 0.061 & 0.025 & 0 & 0.043 & 0.059 & 0.076 & 0.134 \\
\hline Charlson Index 144 & 3.444 & 0.400 & 2.315 & 3.196 & 3.476 & 3.700 & 4.363 \\
\hline Charlson Index Ind. 144 & 0.233 & 0.667 & 0 & 0 & 0 & 0 & 3.250 \\
\hline Mortality Rate 144 & 0.015 & 0.011 & 0 & 0.008 & 0.014 & 0.020 & 0.060 \\
\hline Charlson Index 296 & 3.452 & 0.476 & 2.086 & 3.165 & 3.476 & 3.750 & 4.595 \\
\hline Charlson Index Ind. 296 & 0.184 & 0.551 & 0 & 0 & 0 & 0 & 3.000 \\
\hline Mortality Rate 296 & 0.016 & 0.010 & 0 & 0.008 & 0.014 & 0.022 & 0.048 \\
\hline \multicolumn{8}{|c|}{ Hospital-Level Control Variables } \\
\hline Benchmark Dummy & 0.109 & 0.312 & 0 & 0 & 0 & 0 & 1 \\
\hline P4P Dummy & 0.503 & 0.500 & 0 & 0 & 1 & 1 & 1 \\
\hline Revenues in 000s & 529,218 & 562,417 & 9,149 & 145,342 & 334,718 & 716,537 & $3,081,531$ \\
\hline Net Income in 000s & 9,075 & 20,605 & $-30,071$ & -520 & 3,070 & 11,179 & 94,391 \\
\hline Total Assets in 000s & 181,822 & 234,249 & 3,123 & 43,097 & 104,975 & 211,894 & $1,374,073$ \\
\hline $\mathrm{ROA}_{\mathrm{t}-1}$ & 0.027 & 0.105 & -0.363 & -0.011 & 0.033 & 0.078 & 0.314 \\
\hline Zscore & 4.555 & 2.051 & 0.620 & 3.052 & 4.164 & 5.693 & 11.057 \\
\hline \%Medicare & 46.688 & 14.065 & 12.051 & 38.276 & 47.506 & 56.929 & 77.984 \\
\hline CMI & 1.117 & 0.213 & 0.740 & 0.970 & 1.080 & 1.230 & 1.807 \\
\hline Teaching Dummy & 0.244 & 0.430 & 0 & 0 & 0 & 0 & 1 \\
\hline Discharges & 10,721 & 7,722 & 310 & 4,170 & 9,392 & 15,612 & 31,598 \\
\hline Log Discharges & 8.930 & 0.970 & 5.737 & 8.336 & 9.148 & 9.656 & 10.351 \\
\hline Boardsize & 15.22 & 5.28 & 2 & 12 & 15 & 18 & 30 \\
\hline Log Boardsize & 2.645 & 0.440 & 0.693 & 2.485 & 2.708 & 2.890 & 3.401 \\
\hline System Dummy & 0.540 & 0.499 & 0 & 0 & 1 & 1 & 1 \\
\hline Rural Dummy & 0.161 & 0.368 & 0 & 0 & 0 & 0 & 1 \\
\hline Church Dummy & 0.146 & 0.353 & 0 & 0 & 0 & 0 & 1 \\
\hline \multicolumn{8}{|c|}{ Hospital-Market-Level Control Variables } \\
\hline HHI & 0.230 & 0.245 & 0.015 & 0.053 & 0.157 & 0.358 & 1 \\
\hline $\begin{array}{l}\text { Median Household } \\
\text { Income in \$ }\end{array}$ & 47,586 & 10,346 & 30,915 & 40,007 & 44,360 & 53,564 & 74,557 \\
\hline $\begin{array}{l}\text { Log Median } \\
\text { Household Income }\end{array}$ & 10.748 & 0.212 & 10.339 & 10.597 & 10.700 & 10.889 & 11.219 \\
\hline
\end{tabular}


Table 6. Probability of being convicted for upcoding

Panel A. Logistic regression estimation of the probability of being convicted for upcoding during 1996 to $1998^{\mathrm{a}}$

\begin{tabular}{lcc}
\hline Variables & Pred. & Conviction Dummy \\
\hline Predictor Variables & - & \\
\hline \%Indigents & - & $-30.696^{*}(0.054)$ \\
Resident-to-Bed Ratio & $-4.531^{* *}(0.021)$ \\
\hline Hospital-Level Control Variables & \\
\hline Benchmark Dummy & $0.955^{* *}(0.039)$ \\
P4P Dummy & $0.388(0.426)$ \\
ROA & $3.730(0.335)$ \\
Zscore & $-0.096(0.584)$ \\
\%Medicare & $-1.077(0.609)$ \\
Log Discharges & $3.218^{* *}(0.013)$ \\
Log Boardsize & $0.035(0.942)$ \\
System Dummy & $0.860(0.229)$ \\
Rural Dummy & $2.255^{* * *}(0.002)$ \\
Church Dummy & $-1.147(0.206)$ \\
\hline Hospital-Market-Level Control Variables & $1.906^{* * *}(<0.001)$ \\
\hline HHI & \\
Log Median Household Income & $2.802^{* *}(0.038)$ \\
Constant & $0.595(0.701)$ \\
Year Dummies & $-16.520(0.273)$ \\
Clustered by & Yospital \\
R-squared & 557 \\
\hline Notes $T a b l 6$, Panel $A:$ & 0.345 \\
\hline
\end{tabular}

Notes to Table 6, Panel A:

${ }^{a} p$-values in parentheses, ${ }^{* * *} p<0.01, * * p<0.05, * p<0.1$ (two-tailed), year dummies included but not reported, standard errors clustered by hospital, variables are winsorized at $1 \%$ and $99 \%$ levels. See Table 3 for variable definitions. 


\begin{tabular}{lc} 
Variables & Marginal Effects \\
\hline \%Indigents & .024 \\
\hline Probability of \%Indigents at Upper Quartile & .055 \\
Probability of \%Indigents at Lower Quartile & -.031 \\
Interquartile Marginal Change & .12 \\
Unconditional Probability of Conviction & $-25.8 \%$ \\
Interquartile Marginal Change in Probability of Conviction for Upper Quartile & \\
& \\
Resident-to-Bed Ratio & .020 \\
\hline Probability of Resident-to-Bed Ratio at Upper Decile & .040 \\
Probability of Resident-to-Bed Ratio at Lower Decile & -.02 \\
Interdecile Marginal Change & .12 \\
Unconditional Probability of Conviction & $-16.7 \%$ \\
Interdecile Marginal Change in Conviction for Upper Decile & \\
\hline Notes to Table 6, Panel B: & \\
$b$ The marginal effects presented here are calculated based on model 1 as reported in Table 6, Panel A. All variables \\
except for \%Indigents and Resident-to-Bed Ratio, respectively, are at their mean values to calculate the probabilities \\
at upper and lower quartile and decile of \%Indigents and Resident-to-Bed Ratio, respectively. The unconditional \\
probability of conviction is the number of convicted hospitals relative to the total number of hospitals.
\end{tabular}

Panel C. Comparison of coding behavior across sample periods ${ }^{c}$

\begin{tabular}{|c|c|c|c|}
\hline & 1996-1998 & 1999-2007 & \\
\hline Variable & Mean & Mean & $\begin{array}{c}\text { Difference } \\
\text { (1996-1998 to 1999-2007) }\end{array}$ \\
\hline \multicolumn{4}{|l|}{ Dependent Variables } \\
\hline DRG Ratio 79 & 0.281 & 0.228 & $0.053 * * *$ \\
\hline DRG Ratio 144 & 0.122 & 0.146 & $-0.024 * * *$ \\
\hline DRG Ratio 296 & 0.357 & 0.337 & $0.020 * * *$ \\
\hline \multicolumn{4}{|c|}{ Patient-Level Control Variables } \\
\hline Charlson Index 79 & 4.136 & 4.282 & $-0.146 * * *$ \\
\hline Mortality Rate 79 & 0.067 & 0.061 & $0.006 * * *$ \\
\hline Charlson Index 144 & 3.276 & 3.444 & $-0.168 * * *$ \\
\hline Mortality Rate 144 & 0.015 & 0.015 & 0 \\
\hline Charlson Index 296 & 3.362 & 3.452 & $-0.09 * * *$ \\
\hline Mortality Rate 296 & 0.016 & 0.016 & 0 \\
\hline
\end{tabular}

Notes to Table 6, Panel C:

${ }^{\mathrm{c}}$ The differences in coding behavior presented here are based on the mean values as reported in Tables 4 and 5. 
Table 7. Seemingly unrelated regression estimation of upcoding as a function of beneficence for years 1999 to $2007(\mathrm{~N}=1,447)^{\mathrm{a}}$

\begin{tabular}{|c|c|c|c|c|}
\hline Variables & Pred. & $\begin{array}{l}\text { DRG Ratio79 } \\
\text { (High Incentives) }\end{array}$ & $\begin{array}{l}\text { DRG Ratio144 } \\
\text { (Medium Incentives) }\end{array}$ & $\begin{array}{l}\text { DRG Ratio296 } \\
\text { (Low Incentives) }\end{array}$ \\
\hline \multicolumn{5}{|l|}{ Predictor Variables } \\
\hline \%Indigents & + & $0.263 * * *(0.002)$ & $0.138 * *(0.038)$ & $0.032(0.707)$ \\
\hline Resident-to-Bed Ratio & + & $0.026 *(0.064)$ & $0.065^{* * *}(<0.001)$ & $0.024 *(0.085)$ \\
\hline \multicolumn{5}{|c|}{ Patient-Level Control Variables } \\
\hline DRG Ratio $\mathrm{X}_{\mathrm{t}-1}$ & & $0.726 * * *(<0.001)$ & $0.695 * * *(<0.001)$ & $0.500 * * *(<0.001)$ \\
\hline Charlson Index X & & $0.022 * * *(<0.001)$ & $0.004(0.239)$ & $0.033^{* * *}(<0.001)$ \\
\hline $\begin{array}{l}\text { Charlson Index } \\
\text { Indigents X }\end{array}$ & & $0.002(0.310)$ & $0.002(0.235)$ & $-0.001(0.970)$ \\
\hline Mortality Rate X & & $0.313^{* * *}(<0.001)$ & $0.461 * * *(<0.001)$ & $0.513 * * *(<0.001)$ \\
\hline \multicolumn{5}{|c|}{ Hospital-Level Control Variables } \\
\hline Benchmark Dummy & & $0.008 *(0.080)$ & $-0.003(0.345)$ & $0.003(0.433)$ \\
\hline P4P Dummy & & $-0.001(0.651)$ & $-0.002(0.270)$ & $-0.002(0.563)$ \\
\hline $\mathrm{ROA}_{\mathrm{t}-1}$ & & $0.011(0.407)$ & $-0.007(0.505)$ & $-0.003(0.836)$ \\
\hline Zscore & & $-0.002 * *(0.022)$ & $-0.001(0.718)$ & $0.001(0.593)$ \\
\hline \%Medicare & & $0.013(0.256)$ & $-0.017 *(0.054)$ & $0.001(0.936)$ \\
\hline CMI & & $0.013 *(0.095)$ & $0.023^{* * *}(<0.001)$ & $0.010(0.232)$ \\
\hline Log Discharges & & $-0.002(0.328)$ & $0.004^{* *}(0.015)$ & $-0.009 * * *(<0.001)$ \\
\hline Log Boardsize & & $-0.001(0.893)$ & $0.004(0.103)$ & $0.001(0.954)$ \\
\hline Church Dummy & & $-0.005(0.211)$ & $-0.001(0.859)$ & $0.002(0.553)$ \\
\hline System Dummy & & $0.006 * *(0.046)$ & $0.002(0.339)$ & $0.010 * * *(<0.001)$ \\
\hline Rural Dummy & & $-0.004(0.456)$ & $-0.007 *(0.058)$ & $-0.007(0.183)$ \\
\hline \multicolumn{5}{|c|}{ Hospital-Market-Level Control Variables } \\
\hline HHI & & $-0.026 * * *(0.001)$ & $-0.001(0.848)$ & $0.007(0.364)$ \\
\hline $\begin{array}{l}\text { Log Median Household } \\
\text { Income }\end{array}$ & & $0.0130 *(0.099)$ & $-0.006(0.347)$ & $-0.003(0.703)$ \\
\hline Constant & & $-0.208 * *(0.015)$ & $-0.043^{* *}(0.011)$ & $0.139(0.112)$ \\
\hline Year Dummies & & Yes & Yes & Yes \\
\hline Clustered by & & Hospital & Hospital & Hospital \\
\hline Observations & & 1,447 & 1,447 & 1,447 \\
\hline R-squared & & 0.704 & 0.744 & 0.455 \\
\hline
\end{tabular}

Notes to Table 7:

${ }^{a} p$-values in parentheses, $* * * p<0.01,{ }^{* *} p<0.05, * p<0.1$ (two-tailed), year dummies included but not reported, standard errors clustered by hospital, variables are winsorized at $1 \%$ and $99 \%$ levels. See Table 3 for variable definitions. 
Table 8. Seemingly unrelated regression estimation of upcoding as a function of beneficence for years 1996 to $1998(\mathrm{~N}=522)^{\mathrm{a}}$

\begin{tabular}{|c|c|c|c|}
\hline Variables & $\begin{array}{l}\text { DRG Ratio79 } \\
\text { (High Incentives) }\end{array}$ & $\begin{array}{l}\text { DRG Ratio144 } \\
\text { (Medium Incentives) }\end{array}$ & $\begin{array}{l}\text { DRG Ratio296 } \\
\text { (Low Incentives) }\end{array}$ \\
\hline \multicolumn{4}{|l|}{ Predictor Variables } \\
\hline \%Indigents & $-0.030(0.869)$ & $-0.084(0.385)$ & $0.038(0.807)$ \\
\hline Resident-to-Bed Ratio & $0.053 *(0.054)$ & $0.033 * *(0.045)$ & $0.003(0.895)$ \\
\hline \multicolumn{4}{|c|}{ Patient-Level Control Variables } \\
\hline DRG Ratio $\mathrm{X}_{\mathrm{t}-1}$ & $0.705^{* * *}(<0.001)$ & $0.586 * * *(<0.001)$ & $0.468 * * *(<0.001)$ \\
\hline Charlson Index X & $0.016 * *(0.035)$ & $-0.007(0.150)$ & $0.031^{* * *}(<0.001)$ \\
\hline $\begin{array}{l}\text { Charlson Index } \\
\text { Indigent X }\end{array}$ & $0.003(0.180)$ & $0.002(0.389)$ & $0.004 *(0.069)$ \\
\hline Mortality Rate X & $0.381 * * *(0.002)$ & $0.637 * * *(<0.001)$ & $0.290(0.171)$ \\
\hline \multicolumn{4}{|c|}{ Hospital-Level Control Variables } \\
\hline Benchmark Dummy & $0.002(0.848)$ & $-0.007(0.172)$ & $-0.004(0.626)$ \\
\hline P4P Dummy & $-0.005(0.393)$ & $-0.001(0.824)$ & $-0.004(0.495)$ \\
\hline $\mathrm{ROA}_{\mathrm{t}-1}$ & $0.004(0.910)$ & $0.018(0.387)$ & $-0.026(0.413)$ \\
\hline Zscore & $0.001(0.600)$ & $0.002 * *(0.029)$ & $0.001(0.503)$ \\
\hline \%Medicare & $0.027(0.282)$ & $-0.018(0.193)$ & $0.022(0.319)$ \\
\hline CMI & $0.023(0.224)$ & $0.036 * * *(0.001)$ & $0.039 * *(0.021)$ \\
\hline Log Discharges & $-0.001(0.916)$ & $0.013^{* * *}(<0.001)$ & $-0.009 * *(0.032)$ \\
\hline Log Boardsize & $-0.004(0.585)$ & $-0.005(0.235)$ & $-0.001(0.922)$ \\
\hline Church Dummy & $0.012 *(0.096)$ & $0.006(0.127)$ & $0.014^{* *}(0.025)$ \\
\hline System Dummy & $0.001(0.895)$ & $0.001(0.969)$ & $0.003(0.532)$ \\
\hline Rural Dummy & $-0.013(0.255)$ & $0.005(0.408)$ & $0.001(0.929)$ \\
\hline \multicolumn{4}{|c|}{ Hospital-Market-Level Control Variables } \\
\hline HHI & $-0.023(0.147)$ & $0.003(0.719)$ & $0.001(0.921)$ \\
\hline $\begin{array}{l}\text { Log Median Household } \\
\text { Income }\end{array}$ & $-0.011(0.509)$ & $-0.002(0.804)$ & $0.004(0.777)$ \\
\hline Constant & $0.093(0.616)$ & $-0.059(0.573)$ & $0.048(0.770)$ \\
\hline Year Dummies & Yes & Yes & Yes \\
\hline Clustered by & Hospital & Hospital & Hospital \\
\hline Observations & 522 & 522 & 522 \\
\hline R-squared & 0.697 & 0.674 & 0.444 \\
\hline
\end{tabular}

Notes to Table 8:

${ }^{a} p$-values in parentheses, $* * * p<0.01,{ }^{* *} p<0.05, * p<0.1$ (two-tailed), year dummies included but not reported, standard errors clustered by hospital, variables are winsorized at $1 \%$ and $99 \%$ levels. See Table 3 for variable definitions. 